\title{
Functionalization of polyhydromethylsiloxane with nitrogen-containing organic compounds
}

\author{
Maria Owińska $^{1}$ (D) $\cdot$ Aleksandra Chechelska-Noworyta $^{1} \cdot$ Zbigniew Olejniczak $^{2} \cdot$ Magdalena Hasik $^{1}$
}

Received: 23 November 2020 / Accepted: 19 March 2021 / Published online: 13 April 2021

(c) The Author(s) 2021

\begin{abstract}
Linear polyhydromethylsiloxane (PHMS) was functionalized with nitrogen-containing organic compounds: $N$-allylaniline (Naa), $N$-allylcyclohexylamine (Nach), $N$-allylpiperidine (Nap) and 4-vinylpyridine (4VP) via hydrosilylation reaction in the presence of $\mathrm{Pt}^{0}$ complex (Karstedt's catalyst) under mild conditions. Reaction course was followed by FTIR spectroscopy and final hydrosilylation products were characterized by FTIR, ${ }^{1} \mathrm{H},{ }^{29} \mathrm{Si}$ NMR and ${ }^{29} \mathrm{Si}$ MAS-NMR spectroscopies as well as by elemental analysis. Results showed that functionalization of PHMS with $N$-allyl amines took place but in none of the systems it was complete. Hydrosilylation of Naa, Nach and Nap with PHMS led both, to the $\beta$ and $\alpha$ addition products. ${ }^{29} \mathrm{Si}$ NMR spectroscopy showed unequivocally that the reaction of PHMS with 4VP did not occur and the only reactions in the systems were hydrolysis of $\mathrm{Si}-\mathrm{H}$ groups of PHMS followed by condensation of the silanol groups resulting in cross-linking of the polymer. All the functionalized polymers studied in the work contained reactive amine moieties prone to further modifications, therefore exhibit a great potential for various applications.
\end{abstract}

Keywords Polysiloxanes · Polyhydromethylsiloxane $\cdot$ Hydrosilylation of amines $\cdot$ Hydrosilylation of pyridine

\section{Introduction}

Polyhydromethylsiloxane (PHMS) is an organosilicon polymer in which silicon atoms are linked via oxygen atoms and to each silicon atom in the polymer chain one methyl group and one hydrogen atom are attached (general formula: $\left.\left[-\mathrm{CH}_{3}(\mathrm{H}) \mathrm{SiO}-\right]_{\mathrm{n}}\right)$. The chain is terminated on one end with a trimethylsilyl group $\left(\left(\mathrm{CH}_{3}\right)_{3} \mathrm{Si}-\right)$, on the other - with a trimethylsiloxyl group $\left(\left(\mathrm{CH}_{3}\right)_{3} \mathrm{SiO}-\right)$. PHMS is non-toxic, inexpensive and commercially available as a colorless, free flowing liquid differing in the molecular mass range (supplier dependent), soluble in many organic solvents and fairly stable in air and moisture [1].

Because of the presence of reactive $\mathrm{Si}-\mathrm{H}$ side groups, PHMS as well as its copolymers containing dimethylsiloxane

Maria Owińska

owinska@agh.edu.pl

1 Faculty of Materials Science and Ceramics, AGHUniversity of Science and Technology, Al Mickiewicza 30, 30-059 Kraków, Poland

2 The Henryk Niewodniczański Institute of Nuclear Physics, Polish Academy of Sciences, Radzikowskiego 152, 31-342 Kraków, Poland units in the backbone (PHMS-DMS) are widely applied in various fields of chemistry. For example, PHMS served as a safe and inexpensive source of hydride ions in reduction reactions of aldehydes, ketones, esters, imines, etc. [2-5] thus being a valuable reactant in synthetic organic chemistry. PHMS and PHMS-DMS copolymers offer also the possibility to modify chemical structure of polysiloxanes. This fact has a profound influence on both, physical and chemical properties and hence on the applications of this important group of polymeric materials applied as coatings, sealants, greases, medicinal materials or, after cross-linking, as precursors for SiCO ceramics [6-8]. Hence, PHMS and PHMS-DMS copolymers are important compounds in polymer, particularly in siloxane polymer chemistry.

Polysiloxanes functionalized by groups originating from organic compounds, often called organofunctional polysiloxanes are frequently synthesized by hydrosilylation. This reaction involves addition of $\mathrm{Si}-\mathrm{H}$ groups to multiple carbon-carbon or carbon-heteroatom bonds in the presence of a catalyst [9]. In the hydrosilylation of carbon-carbon double bonds, most suitable for the preparation of organofunctional siloxanes $[10,11]$, two platinum compounds: $\mathrm{H}_{2} \mathrm{PtCl}_{6}$ and $\mathrm{Pt}_{2}\left[\mathrm{CH}_{2}=\mathrm{CHSi}\left(\mathrm{CH}_{3}\right)_{2} \mathrm{O}\right]_{3}$ (complex of $\mathrm{Pt}^{0}$ and 1,1,3,3-tetramethyl-1,3-divinyldisiloxane), frequently 
referred to as Speier's and Karstedt's catalysts, respectively, are very efficient and mainly used $[12,13]$. Survey of the literature shows that there are many organic moieties which can be incorporated into polysiloxanes by hydrosilylation. The most important are: epoxy and other oxygen-containing groups (e.g. acrylic and methacrylic ester or acid and polyether moieties), fluoroalkyl and other fluorine-containing groups as well as moieties originating from amines and other nitrogen-containing organic compounds [11].

Introduction of nitrogen-containing organic side groups to polysiloxanes results in the materials that show particularly attractive chemical and/or physical properties. Thus, presence of the nonbonding electron pairs on nitrogen atoms in amine groups allows for the formation of coordinate bonds. Therefore polysiloxanes functionalized by amine groupcontaining moieties can act as ligands for metal ions or particles and can be used, e.g. for extraction of toxic metal ions from waste water [14], as chemical membrane sensors for $\mathrm{Fe}^{3+}$ ions detection in water [15], as supports for metallic catalysts $[16,17]$ or as stabilizers for metal nanoparticles [18]. After transformation into quaternary ammonium salts (QAS) they exhibit antimicrobial properties [19]. Similarly, polysiloxanes modified by other nitrogen-containing organic moieties, e.g. imidazolyl or triazolyl groups, can be applied as carriers for metallic catalysts [20,21]; the latter, in their salt forms, show biocidal activity [22].

Modification of polysiloxanes with aromatic $N$-containing heterocyclic organic moieties having specific electronic structure and hence interesting optical properties leads to the materials suitable for use in various optical devices [23, 24]. Polysiloxanes with introduced carbazolyl side groups, because of the influence of these moieties on the refractive index values and thermo-optical coefficient of the materials can exhibit tunable optical properties [25, 26]. Moreover, polysiloxanes functionalized by the carbazolyl and indolyl moieties were found to be good materials for photorefractive [27, 28] or nonlinear optical [29] applications. Among other nitrogen-containing organic side groups that were used to modify polysiloxanes providing them with interesting thermooptical properties, phthalocyanine [30] can also be mentioned.

Importantly, direct hydrosilylation of amines and other $\mathrm{N}$-containing organic compounds is associated with certain restrictions. Reactions with unsaturated amines in the presence of Pt catalyst may be accompanied by the undesired side processes that result in polymer cross-linking due to the reaction between $\mathrm{Si}-\mathrm{H}$ and $\mathrm{N}-\mathrm{H}$ groups [12] or catalyst poisoning [13]. Inhibiting effect of amines and aminated polymers on Speier's catalyst has been documented [31]. On the other hand, amines are known as additives that act as promoters for Pt hydrosilylation catalysts [13].

In the literature there are, however, also reports on successful hydrosilylation of amines by polymers with $\mathrm{Si}-\mathrm{H}$ groups in their structure. Kanjilal et al. [32] reported the reaction of PHMS with various amounts of $\mathrm{N}$-allylcyclohexylamine, in the presence of $\mathrm{H}_{2} \mathrm{PtCl}_{6}$ as a catalyst (toluene, $70{ }^{\circ} \mathrm{C}$ ). Using cyclohexylamine-functionalized polymers, membranes on porous polyethylene supports were fabricated and applied for pervaporative enrichment of 1,3-propanediol from binary aqueous mixtures. Guerra-Contreras et al. [33] and Lei et al. [19] hydrosilylated $N, N$-dimethylallylamine (DMAA), i.e. a tertiary amine, with PHMS-DMS in the presence of Karstedt's catalyst (anhydrous toluene, $90-100^{\circ} \mathrm{C}$ ) which afforded amine-substituted polysiloxanes. Then Lei et al. [19] introduced PDMS blocks at both termini of the modified copolymer to obtain PDMS/amine-modified PHMS-DMS/PDMS triblock copolymer. In both studies, the synthesized polysiloxanes with amine groups were converted to the QAS by treatment with 1-iodooctane [33] or benzyl chloride [19]. The prepared salts showed good solubility in polar organic solvents, such as ethanol [33] and high antibacterial activity [19]. Chen et al. [34, 35] reported successful hydrosilylation of 4-vinylpyridine (4VP) with PHMSDMS copolymer using Karstedt's catalyst (toluene, $110^{\circ} \mathrm{C}$ ). Antibacterial polysiloxanes with pyridinium pendants were obtained by subsequent $N$-alkylation of pyridine ring with 1-bromohexane [34] or 6-perfluorooctyl-1-bromohexane [35].

It should be noted that, up to our knowledge, in the literature there are no systematic studies on modification of siloxanes or polysiloxanes by hydrosilylation of various nitrogen-containing unsaturated organic compounds in the presence of Pt catalysts. Therefore we decided to conduct systematic investigations in which unsaturated $N$-containing compounds were hydrosilylated by a low-molecular-weight siloxane and a polysiloxane with $\mathrm{Si}-\mathrm{H}$ groups in their structures, i.e. 1, 1, 3, 3-tetramethyldisiloxane $\left(\mathrm{M}_{2}{ }^{\mathrm{H}}\right)$ and PHMS, respectively. This work is a part of the larger scope of research conducted by our group aimed at evaluating feasibility of performing hydrosilylation of $\mathrm{N}$-containing compounds in the presence of a Pt catalyst. It is a continuation of our earlier studies on the hydrosilylation of selected $\mathrm{N}$-allyl compounds: $\mathrm{N}$-allylaniline (Naa), $\mathrm{N}$-allylcyclohexylamine (Nach), $N$-allylpiperidine (Nap) and vinyl nitrogen-containing compounds: 4-vinylpyridine (4VP), 2-vinylpyridine (2VP) by $\mathrm{M}_{2}{ }^{\mathrm{H}}$ catalyzed by Karstedt's catalyst [36]. In the present work, hydrosilylation of these $N$-containing compounds (except for 2VP) by PHMS is reported. The reactions with $\mathrm{N}$-allyl amines were conducted using Karstedt's catalyst under mild conditions - in toluene at $60{ }^{\circ} \mathrm{C}$, while in the case of $4 \mathrm{VP}$, the reaction conditions were modified (with or without toluene, $110{ }^{\circ} \mathrm{C}$ ).

The main aim of the work was to study functionalization of PHMS via hydrosilylation reaction with unsaturated $\mathrm{N}$-containing compounds in the presence of Karstedt's catalyst. We performed the reactions with the polymer in an 
analogous manner like in the case of $\mathrm{M}_{2}{ }^{\mathrm{H}}$ to find out the differences in both, the reaction course and products. We were interested in reactivity of $\mathrm{N}$-allyl and vinyl compounds towards the polymer-in checking whether PHMS functionalization occurs in all of the systems, and in regioselectivity of the reactions, i.e. whether both types of regioisomeric linkages ( $\alpha$-according to Markovnikov's rule and $\beta$-antiMarkovnikov's rule) are formed, or only one of them. Additionally, comparison of the reactions of the selected $\mathrm{N}$-containing compounds with PHMS and the previously studied $\mathrm{M}_{2}{ }^{\mathrm{H}}$ was of interest because it allowed drawing conclusions on the influence on the length of the hydrosiloxane molecule on the result of the process. Such comparison was particularly important in the case of 4VP since our studies showed that it does not react with $\mathrm{M}_{2}{ }^{\mathrm{H}}$ [36], whereas-as already mentioned-there are reports on its successful hydrosilylation with a high-molecular-weight compound, PHMS-DMS copolymer, catalyzed by Karstedt's catalyst [34, 35].

\section{Experimental}

\section{Materials}

PHMS (viscosity: 35-45 cSt, average molecular weight determined by ${ }^{29} \mathrm{Si}$ NMR spectrum of PHMS solution in $\mathrm{CDCl}_{3}$ : $3800 \mathrm{~g} / \mathrm{mol}$ ) was purchased from ABCR (Germany) and vacuum-dried (pressure: $\sim 10^{-2} \mathrm{mbar}$ ) at $60{ }^{\circ} \mathrm{C}$ for $2 \mathrm{~h}$ before use. Platinum(0)-1,3-divinyl-1,1,3,3-tetramethyldisiloxane complex (Karstedt's catalyst) was supplied by Sigma-Aldrich (Poland) as the solution in xylene ( $2 \mathrm{wt} . \%$ of Pt) and used in the work without purification. 4VP, Naa and Nach were purchased from Sigma-Aldrich (Poland) and purified by vacuum distillation before use. Nap was synthesized using the procedure presented in Ref. [36]. Toluene was supplied by Avantor (Poland) and was distilled from sodium-benzophenone prior to use. Piperidine, sodium hydride $60 \%$ mixture in mineral oil and allyl bromide applied in the preparation of Nap, were purchased from ABCR (Germany), Sigma-Aldrich (Poland) and Avantor (Poland), respectively and used in the work without purification. Diethyl ether was purchased from Avantor (Poland) and, before use, dried using benzophenone and sodium, and then distilled under Ar.

\section{Functionalization of PHMS with nitrogen-containing $\mathbf{N}$-allyl compounds}

PHMS was functionalized with $N$-allyl compounds by hydrosilylation performed in the presence of Karstedt's catalyst. Molar ratio of $\mathrm{Si}-\mathrm{H}$ groups from the polymer to $\mathrm{CH}_{2}=\mathrm{CH}_{-} \mathrm{CH}_{2}-$ groups from the nitrogen-containing compound equal to $1: 1.5$ and 1:0.5 were applied.
In a typical run, $2.0 \mathrm{~g}(0.00089 \mathrm{~mol} ; 0.032 \mathrm{~mol}$ of $\mathrm{Si}-\mathrm{H}$ groups) of PHMS (previously dried on a vacuum line), the measured amount of selected $\mathrm{N}$-allyl compound (Naa, Nach or Nap), toluene $(4.0 \mathrm{ml})$ and Karstedt's catalyst solution $\left(0.17 \cdot 10^{-6} \mathrm{~mol}\right.$ of $\left.\mathrm{Pt}\right)$ were successively placed in the flowing $\mathrm{Ar}$ atmosphere in a Schlenk flask. Then the flask was closed, put in an oil bath, and its content, under magnetic stirring, heated to $60{ }^{\circ} \mathrm{C}$. The reaction was carried out at this temperature for $48 \mathrm{~h}$. FTIR spectra of the initial reaction mixture as well as the samples withdrawn after 24 and $48 \mathrm{~h}$ of the process were recoded to monitor the disappearance of the $\mathrm{Si}-\mathrm{H}$ groups from the systems.

In the reactions carried out at $\mathrm{Si}-\mathrm{H}: \mathrm{CH}_{2}=\mathrm{CH}-\mathrm{CH}_{2}-$ groups molar ratio equal to $1: 1.5,6.51 \mathrm{ml}$ of $\mathrm{Naa}, 6.95 \mathrm{ml}$ of Nach and $7.05 \mathrm{ml}$ of Nap $(0.048 \mathrm{~mol})$ were applied. For the ratio 1:0.5 the amounts of $N$-allyl compounds were as follows: $2.17 \mathrm{ml}$ of Naa, $2.32 \mathrm{ml}$ of Nach and $2.35 \mathrm{ml}$ of Nap (0.016 mol).

After the reactions, when liquid products were obtained, toluene was removed by rotary evaporation; then the remaining mixtures were dried on a vacuum line at $60{ }^{\circ} \mathrm{C}$ to distill off the unreacted $\mathrm{N}$-containing compound. This method was sufficient to separate PHMS functionalized by Naa and $\mathrm{Nach}$ at the $\mathrm{Si}-\mathrm{H}: \mathrm{CH}_{2}=\mathrm{CH}-\mathrm{CH}_{2}-$ group's molar ratio equal to 1:1.5 and Nap at both molar ratios. In the case of solid samples, i. e. PHMS treated with Naa and Nach at the molar ratio equal to $1: 0.5$, another procedure of purification was applied. Materials were washed few times with anhydrous toluene on a Büchner funnel in order to remove all unreacted $\mathrm{N}$-containing compound from the sample. The presence of unreacted organic compounds in the collected filtrates was detected using gas chromatography (GC). Then the obtained products were dried on a vacuum line at $60{ }^{\circ} \mathrm{C}$.

In the following parts of the paper, the symbols: PHMS_Naa_1.5, PHMS_Nach_1.5, PHMS_Nap_1.5 and PHMS_Naa_0.5, PHMS_Nach_0.5, PHMS_Nap_0.5 will be used to denote PHMS functionalized with the appropriate $\mathrm{N}$-allylamine at the $\mathrm{Si}-\mathrm{H}: \mathrm{CH}_{2}=\mathrm{CH}-\mathrm{CH}_{2}$ - groups molar ratios equal to $1: 1.5$ and $1: 0.5$, respectively.

\section{Functionalization of PHMS with 4-vinylpyridine}

Functionalization of PHMS with 4-vinylpyridine (4VP) was performed in an analogous manner to functionalization of the polymer with $N$-allyl compounds described in the previous section introducing, however, some modifications. The reactions were performed with and without solvent (toluene) and applying four different $\mathrm{Si}-\mathrm{H}: \mathrm{CH}_{2}=\mathrm{CH}$ - groups molar ratios equal to $1: 1.5 ; 1: 1 ; 1: 0.5$ or $1: 0.25$ using $5.20 \mathrm{ml}$ $(0.048 \mathrm{~mol}), 3.36 \mathrm{ml}(0.032 \mathrm{~mol}), 1.73 \mathrm{ml}(0.016 \mathrm{~mol})$ or $0.84 \mathrm{ml}(0.008 \mathrm{~mol})$ of $4 \mathrm{VP}$ per $2 \mathrm{~g}$ of PHMS, respectively. 
The reactions were carried out in an argon atmosphere at $110^{\circ} \mathrm{C}$ for $48 \mathrm{~h}$. FTIR spectra of the initial reaction mixture as well as the samples withdrawn after 24 and $48 \mathrm{~h}$ of the process served as the basis for establishing the disappearance of the $\mathrm{Si}-\mathrm{H}$ groups from the systems. The obtained products (all of the samples were insoluble solids) were subjected to extraction using dry toluene in a Soxhlet apparatus for $24 \mathrm{~h}$ in order to remove the unreacted $4 \mathrm{VP}$ and then dried on a vacuum line at $60{ }^{\circ} \mathrm{C}$.

The PHMS samples functionalized with $4 \mathrm{VP}$ at $\mathrm{Si}-\mathrm{H}: \mathrm{CH}_{2}=\mathrm{CH}-$ groups molar ratios equal to $1: 1.5 ; 1: 1$; 1:0.5 and 1:0.25 will be referred to as: PHMS_4VP_1.5, PHMS_4VP_1, PHMS_4VP_0.5 and PHMS_4VP_0.25, respectively.

\section{Characterization methods}

${ }^{1} \mathrm{H}$ NMR and ${ }^{29} \mathrm{Si}$ NMR spectra were recorded on a Bruker Avance III HD (400 MHz) Spectrometer, using $\mathrm{CDCl}_{3}$ ( $\delta=7.26 \mathrm{ppm}$ ) as solvent. Fourier transform infrared (FTIR) spectra were recorded on a FTIR (BIO-RAD Excalibur) spectrometer, equipped with a horizontal zinc selenide (ZnSe) ATR sampling accessory. Spectra were obtained after collecting 32 scans in the 4000 to $550 \mathrm{~cm}^{-1}$ range; incident beam angle was equal to $45^{\circ}$. Elemental analyses were taken on a Vario El III analyzer (Elementar Analysensysteme $\mathrm{GmbH}$ ) after combustion of the analyzed sample in oxygen at $1150{ }^{\circ} \mathrm{C}$. Contents of $\mathrm{C}, \mathrm{H}, \mathrm{N}$ in the samples reported in the work are the average values of two analyses. The contents of $\mathrm{Si}$ and $\mathrm{O}$ in the samples were calculated as the difference: $100 \%-\Sigma \mathrm{C}, \mathrm{H}, \mathrm{N}$. Gas chromatographic analyses were performed on a Shimadzu GC2010 chromatograph equipped with thermal conductivity detector (TCD) and Zebron ZB-1 capillary column (diameter $0.25 \mathrm{~mm}$, length
$30 \mathrm{~m}$, liquid phase: polydimethylsiloxane) using helium as a carrier gas. The following temperature program was used in chromatographic analyses of the unreacted $\mathrm{N}$-allyl compounds: detector temperature $250{ }^{\circ} \mathrm{C}$, sample evaporation temperature $250{ }^{\circ} \mathrm{C}$, working column temperature-initial $60{ }^{\circ} \mathrm{C}$ maintained for $3 \mathrm{~min}$, then increased to $240{ }^{\circ} \mathrm{C}$ at the rate of $18^{\circ} \mathrm{C} / \mathrm{min}$.

High resolution, solid state ${ }^{29} \mathrm{Si}$ MAS-NMR spectra were measured on a Tecmag APOLLO pulse NMR spectrometer at the magnetic field of $7.05 \mathrm{~T}$ generated by the Magnex wide bore superconducting magnet. A Bruker HP-WB highspeed MAS probe equipped with the $4 \mathrm{~mm}$ zirconia rotor and KEL-F cap was used to record the MAS spectra at the spinning speed of $4 \mathrm{kHz}$. The spectra were measured at $59.515 \mathrm{MHz}$, using a single $3 \mu$ s radio-frequency (rf) pulse, corresponding to $\pi / 2$ flipping angle. The acquisition delay used in accumulation was $30 \mathrm{~s}$, and 128-384 scans were acquired, depending on the signal strength. The spectra were normalized to the same mass and number of accumulations. The frequency scale in ppm was referenced to the ${ }^{29} \mathrm{Si}$ resonance of tetramethylsilane (TMS).

\section{Results and discussion}

In the work, hydrosilylation of carbon-carbon double bonds present in allyl groups of Naa, Nach and Nap as well as those occurring in vinyl group of 4VP with PHMS using Karstedt's catalyst was carried out. Conducted reactions are schematically depicted in Fig. 1. The scheme shows that as a result of the addition reaction both regioisomeric linkages, $\alpha$ (according to Markovnikov's rule) and $\beta$ (anti-Markovnikov's rule), can be formed in the polymer molecule. In many hydrosilylation processes, however, the $\beta$ addition prevails [12]. The purpose of the experiments was to check whether

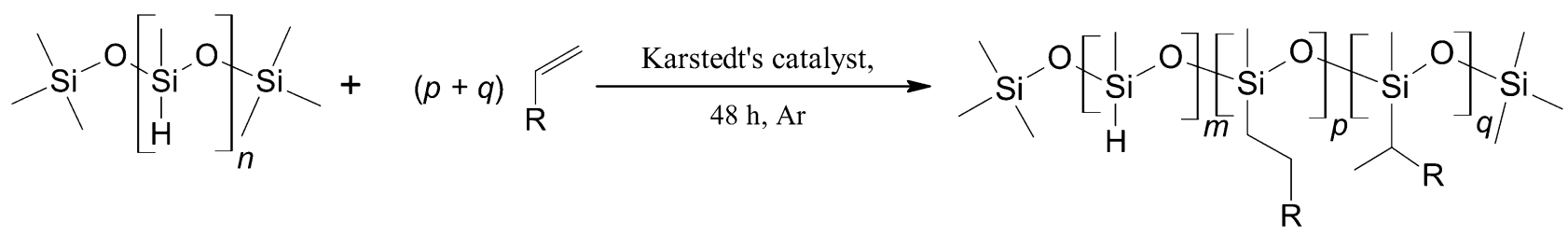<smiles>[R]=Nc1ccccc1NCCCCNC1CCCCC1</smiles>

Fig. 1 Scheme of reactions of PHMS with the studied nitrogen-containing organic compounds 
PHMS functionalization occurs in each of the systems and whether both types of linkages ( $\alpha$ and $\beta$ ) are formed during the reaction, or only one of them.

Results of the investigations, separately for $\mathrm{N}$-allyl compounds and $4 \mathrm{VP}$, will be discussed in the following sections.

\section{Functionalization of PHMS with $\mathbf{N}$-allyl compounds}

During the functionalization of PHMS with $N$-allyl compounds, the reaction progress was monitored by FTIR spectroscopy, analyzing the spectra of the initial reaction mixture, the sample withdrawn after $24 \mathrm{~h}$ of the process as well as the final reaction mixture ( $48 \mathrm{~h}$ of the process, Experimental Section).

FTIR spectra of all reaction mixtures show gradual lowering in the intensities of the bands corresponding to the $\mathrm{Si}-\mathrm{H}$ groups, thus marking the progress of PHMS modification processes. This is illustrated by Fig. 2 in which the decrease in intensity of the band assigned to the stretching vibrations of the $\mathrm{Si}-\mathrm{H}$ groups [37] at $\sim 2160 \mathrm{~cm}^{-1}$ in the spectra recorded during modification of PHMS with Nap is presented.

In none of the studied systems the disappearance of the band attributed to $\mathrm{Si}-\mathrm{H}$ groups was complete, which indicates only partial functionalization of the polymer. This is understood in case of the reactions in which excessive amounts of $\mathrm{Si}-\mathrm{H}$ groups with respect to allyl groups were applied ( $\mathrm{Si}-\mathrm{H}: \mathrm{CH}_{2}=\mathrm{CH}-\mathrm{CH}_{2}$ - ratio equal to $1: 0.5)$. In the reactions with the excess of allyl moieties ( $\mathrm{Si}-\mathrm{H}: \mathrm{CH}_{2}=\mathrm{CH}-\mathrm{CH}_{2}$ - ratio equal to 1:1.5) preservation of some $\mathrm{Si}-\mathrm{H}$ groups must have been due to steric limitations.

Comparing the ratios of integral intensities of $\mathrm{Si}-\mathrm{H}$ (at $2160 \mathrm{~cm}^{-1}$ ) and $\mathrm{Si}-\mathrm{CH}_{3}\left(\right.$ at $\left.\sim 1250 \mathrm{~cm}^{-1}\right)$ bands in the FTIR spectra of PHMS and final reaction mixtures, the final conversion degrees of the $\mathrm{Si}-\mathrm{H}$ groups were estimated (as described in Ref. [38, 39]). They were equal to: 84.7\% (PHMS_Naa_1.5), 62.8\% (PHMS_Naa_0.5), 61.2\% (PHMS_Nach_1.5), 46.5\% (PHMS_Nach_0.5), 93.6\% (PHMS_Nap_1.5), 59.9\% (PHMS_Nap_0.5). Higher conversion degrees of the $\mathrm{Si}-\mathrm{H}$ groups were found in all systems with the molar ratio of $\mathrm{Si}-\mathrm{H}: \mathrm{CH}_{2}=\mathrm{CH}-\mathrm{CH}_{2}$ - groups equal to $1: 1.5$ which suggests that the excess of $\mathrm{N}$-allyl compound relative to the polymer allows achieving higher degrees of functionalization.

Additionally, it can be noticed that the conversion of $\mathrm{Si}-\mathrm{H}$ groups determined on the basis of FTIR spectra in the reactions conducted with the excess of Naa and Nach is lower than in the respective systems in which $\mathrm{M}_{2}{ }^{\mathrm{H}}$ was the reagent $\left(\mathrm{M}_{2}{ }^{\mathrm{H}} / \mathrm{Naa}-\mathrm{Si}-\mathrm{H}\right.$ groups conversion rate $=98.6 \%, \mathrm{M}_{2}{ }^{\mathrm{H}} / \mathrm{Nach}-$ $\mathrm{Si}-\mathrm{H}$ groups conversion rate $=97.0 \%$, Ref. [36]). This can be explained by differences in molecular structure of PHMS and $\mathrm{M}_{2}{ }^{\mathrm{H}}$ : in the polymer chain the $\mathrm{Si}-\mathrm{H}$ groups are adjacent and the reaction of $\mathrm{N}$-allyl compounds with all $\mathrm{Si}-\mathrm{H}$ groups is difficult. Linkages formed between silicon atoms in the polymer chain and carbon atoms from $N$-allyl compounds cause steric hindrance which limits the amount of organic moieties introduced into the system. This restriction does not occur in the case of $\mathrm{M}_{2}{ }^{\mathrm{H}}$, where $\mathrm{Si}-\mathrm{H}$ groups are located at the ends of the molecule. Moreover, the influence of the chain length on the reaction course can be considered. The polymer, whose chains are considerably longer than those of $\mathrm{M}_{2}{ }^{\mathrm{H}}$, is a more viscous liquid than $\mathrm{M}_{2}^{\mathrm{H}}$. During functionalization, due to the increase in the molecular weight of the products with respect to those of the starting compounds, viscosity of the reaction medium grows. It must be higher in the reactions of PHMS than in those of $\mathrm{M}_{2}{ }^{\mathrm{H}}$ because of longer polymer chains and higher molecular weight of macromolecules with incorporated moieties of $\mathrm{N}$-allyl amines as compared to the molecules of functionalized $\mathrm{M}_{2}{ }^{\mathrm{H}}$. Although
Fig. 2 FTIR spectra showing the decrease of the $\mathrm{Si}-\mathrm{H}$ stretching vibrational band during preparation of a PHMS_Nap_0.5 sample and b PHMS_Nap_1.5 sample
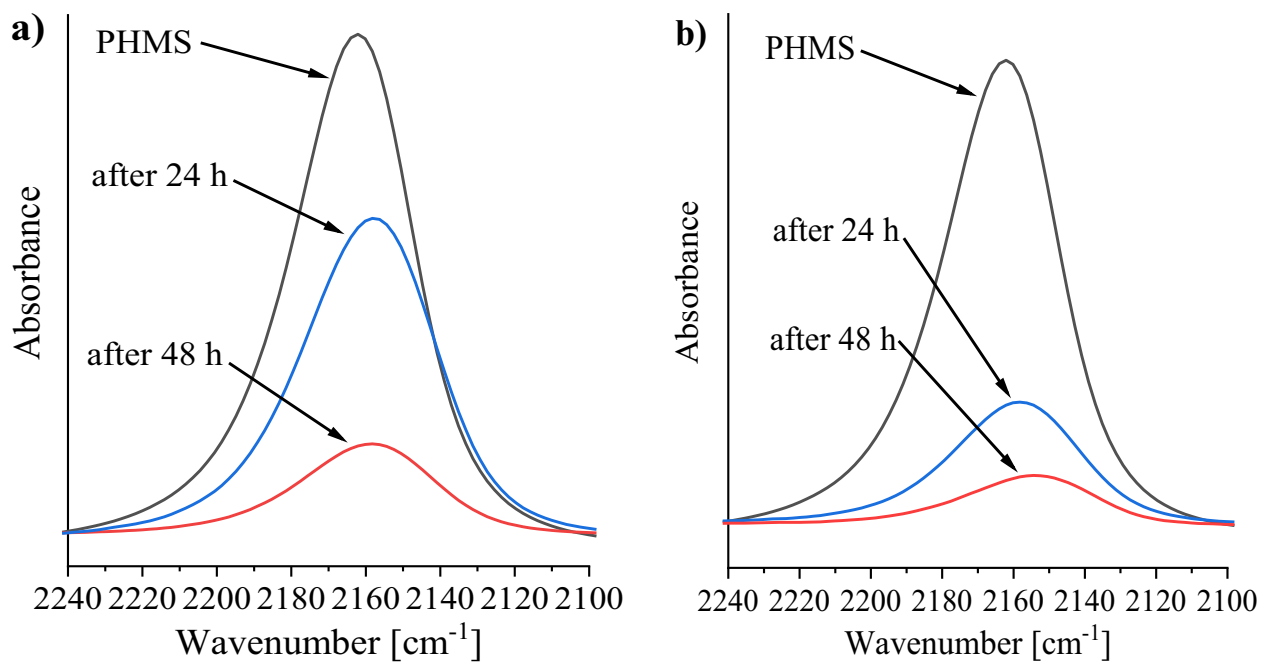
this problem has not been studied in the work (viscosity or diffusion rates were not measured), it can be supposed that increased viscosity results in slower rate of reactants' diffusion in the systems and this may lead to lower conversion of $\mathrm{Si}-\mathrm{H}$ groups present in the polymer than those existing in $\mathrm{M}_{2}{ }^{\mathrm{H}}$. Similar effect would be observed if PHMS contained a significant fraction of high-molecular-weight macromolecules. In practice, however, this seems unlikely owing to the known difficulties with the synthesis of PHMS showing high molecular weight.

Higher conversion degrees of Si-H groups in PHMS_Naa than in the corresponding PHMS_Nach systems prove in turn that the presence of a rigid and planar aromatic ring in the Naa molecule is beneficial for the functionalization of the polymer. $\mathrm{M}_{2}{ }^{\mathrm{H}}$ functionalization studies using Naa led to similar conclusion [36].

The highest conversion degrees of the $\mathrm{Si}-\mathrm{H}$ groups in the PHMS_Nap_1.5 system in comparison with PHMS_Naa_1.5 and PHMS_Nach_1.5, as well as small differences in conversion degrees of the $\mathrm{Si}-\mathrm{H}$ groups in the reactions of $\mathrm{M}_{2}{ }^{\mathrm{H}}$ and PHMS with the excess of Nap $\left(\mathrm{M}_{2}{ }^{\mathrm{H}} / \mathrm{Nap}\right.$ - conversion degree of the $\mathrm{Si}-\mathrm{H}$ groups $=91.1 \%$, Ref. [36]) indicate that the molecular structure of Nap-despite the non-planar, flexible aliphatic ring [40, 41] - does not constitute a significant obstacle for polymer functionalization.

All samples obtained by the reactions of PHMS with the excess of Naa, Nach and Nap (PHMS_Naa_1.5, PHMS Nach_1.5 and PHMS_Nap_1.5) were liquid. Reactions of PHMS using deficient amount of an amine with respect to PHMS led to the formation of brittle and insoluble solids in case of Naa and Nach (PHMS_Naa_0.5 and PHMS _ Nach_0.5) and to a liquid sample which solidified after storage for some time in air in case of Nap (PHMS_Nap_0.5). Only samples functionalized with Nach were colorless, the other ones were yellow.

Formation of liquid products was expected because PHMS is liquid and the $N$-allyl compounds used in the work for its modification contained only one reactive, allyl group in the molecules and could not act as PHMS cross-linking agents. Formation of solid, insoluble products during the reaction of PHMS with Naa and Nach at the molar ratio of $\mathrm{Si}-\mathrm{H}: \mathrm{CH}_{2}=\mathrm{CH}-\mathrm{CH}_{2}$ - groups equal to 1:0.5 proves, however, that hydrosilylation in these systems was accompanied by side processes that resulted in polymer cross-linking. Most probably, it was caused by condensation of silanol groups $(\mathrm{Si}-\mathrm{OH})$, resulting from hydrolysis of a fraction out of a large number of $\mathrm{Si}-\mathrm{H}$ groups present in PHMS. Functionalization was carried out in an argon atmosphere (Experimental Section), but it cannot be excluded that during the 48-h process air got into the reaction flasks and water contained in it caused hydrolysis of some $\mathrm{Si}-\mathrm{H}$ groups. The transformation of the initially liquid PHMS_Nap_0.5 sample after storage confirms the cross-linking of the polymer in the air atmosphere. The fact that a solid sample was not formed in this case immediately after the reaction shows that hydrolysis of Si-H groups in PHMS_Nap_0.5 was slower than in PHMS_Naa_0.5 and PHMS_Nach_0.5 systems.

FTIR spectra of the final, purified products confirm that the reactions between PHMS and $N$-allyl compounds do occur but are not complete. In the spectra of all the studied samples (Fig. 3) the band at $2158 \mathrm{~cm}^{-1}$ due to the unreacted $\mathrm{Si}-\mathrm{H}$ groups is clearly visible. This band is more intensive in the spectra of the samples obtained with excessive amounts of $\mathrm{Si}-\mathrm{H}$ groups with respect to allyl ones ( $\mathrm{Si}-\mathrm{H}: \mathrm{CH}_{2}=\mathrm{CH}-\mathrm{CH}_{2}$ - equal to 1:0.5). Lower conversion degrees of $\mathrm{Si}-\mathrm{H}$ groups, and therefore their higher content in the final samples obtained at the ratio to 1:0.5, were found, as already mentioned, on the basis of quantitative analysis of the spectra of the final reaction mixtures.

All the spectra contain also characteristic bands for siloxane fragments originating from: asymmetric stretching vibrations of $\mathrm{Si}-\mathrm{O}-\mathrm{Si}$ groups $\left(1130-1000 \mathrm{~cm}^{-1}\right)$ as well as from $\mathrm{C}-\mathrm{H}$ bond in $\mathrm{Si}-\mathrm{CH}_{3}$ groups vibrations: symmetric $\left(1259 \mathrm{~cm}^{-1}\right)$ and asymmetric $\left(1410 \mathrm{~cm}^{-1}\right)$ bending and symmetric $\left(2927 \mathrm{~cm}^{-1}\right)$ and asymmetric $\left(2962 \mathrm{~cm}^{-1}\right)$ stretching [37, 38, 42]. Besides the bands characteristic for the siloxane part of the molecule, in the FTIR spectra, the bands

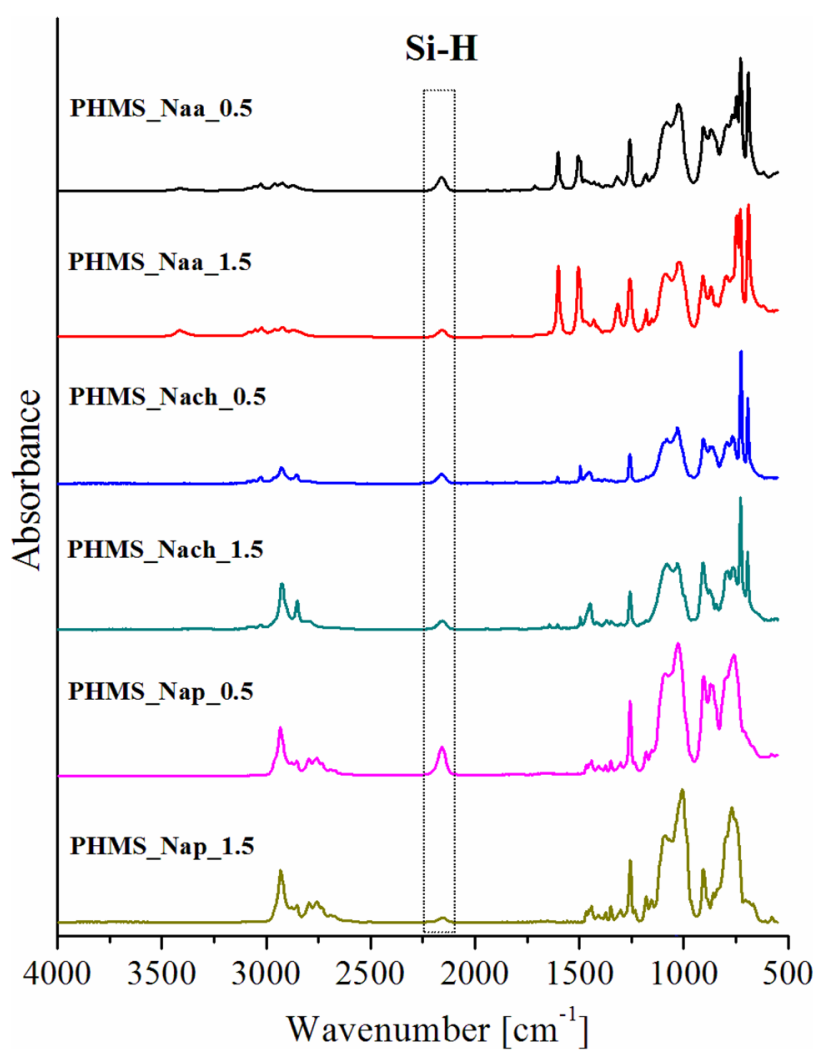

Fig. 3 FTIR spectra of the final, purified products of PHMS modification by $\mathrm{N}$-allyl compounds 
characteristic for nitrogen-containing compounds used for PHMS functionalization can be distinguished. The spectra of PHMS_Naa_1.5 and PHMS_Naa_0.5 contain the bands at $3024 \mathrm{~cm}^{-1}$ and $1505 \mathrm{~cm}^{-1}$ due to $\mathrm{C}-\mathrm{H}$ and $\mathrm{C}=\mathrm{C}$ stretching vibrations of aromatic ring, respectively and also the bands at $3414 \mathrm{~cm}^{-1}$ and $1602 \mathrm{~cm}^{-1}$. The former can be unambiguously ascribed to $\mathrm{N}-\mathrm{H}$ stretching vibrations [37], whereas the band at $1602 \mathrm{~cm}^{-1}$ is probably the superposition of a weak band due to $\mathrm{C}=\mathrm{C}$ stretching vibrations of the aromatic ring and an intense band ascribed to $\mathrm{N}-\mathrm{H}$ deformation vibrations [37]. Due to differences in their intensities, the latter band should be the predominant component in this spectral region. The weak band at $1180 \mathrm{~cm}^{-1}$ which is visible in the spectra of all samples, can be ascribed to $\mathrm{C}-\mathrm{N}$ bond stretching vibrations in $N$-containing side groups in the final PHMS functionalization products [37].

Additionally, FTIR spectra of all the studied samples show the band at $2852 \mathrm{~cm}^{-1}$ attributed to $-\mathrm{CH}_{2}$ - groups. The assignment of this band in the spectra is ambiguous. It may come from vibrations of $\mathrm{C}-\mathrm{H}$ bonds in propylene bridges $\left(-\mathrm{CH}_{2} \mathrm{CH}_{2} \mathrm{CH}_{2}-\right)$ at silicon atoms resulting from hydrosilylation. In the spectra of PHMS functionalized by units originating from Nach or Nap, however, this band should be considered as a combination of the bands originating from $\mathrm{Si}-\mathrm{CH}_{2}-\mathrm{CH}_{2}-\mathrm{CH}_{2}$ - and $-\mathrm{CH}_{2}-$ groups present in the Nach and Nap rings (Fig. 1). In addition, possible existence of the unreacted $N$-allyl compounds in the final samples after purification step (Experimental Section) may be also the reason for the appearance of the band due to $-\mathrm{CH}_{2}$ - groups in the spectra. Therefore, in the case of hydrosilylation of $\mathrm{N}$-allyl compounds with PHMS, it was necessary to perform NMR spectroscopy investigations to corroborate unambiguously formation of polymer functionalization products.

Analysis of the ${ }^{1} \mathrm{H}$ NMR spectra of PHMS_Naa_1.5 (Fig. 4), PHMS_Nach_1.5 (Fig. 5), PHMS_Nap_1.5 and PHMS_Nap_0.5 materials (Fig. 6) corroborated that the reactions between PHMS and $N$-allyl compounds do occur. The proton signals seen in the spectra were assigned based on the experimental and simulated ${ }^{1} \mathrm{H}$ NMR spectra of the analogous modified disiloxane, $\mathrm{M}_{2}{ }^{\mathrm{H}}$ described in Ref. [36]. The measured spectra of the modified PHMS (Fig. 4 - Fig. 6) contain the lines at similar chemical shift values to those found in the spectra of the modified $\mathrm{M}_{2}{ }^{\mathrm{H}}$. However, signals visible in the spectra of the polymer are broader than the ones occurring in the spectra of the functionalized disiloxane which is typical of polymeric materials due to

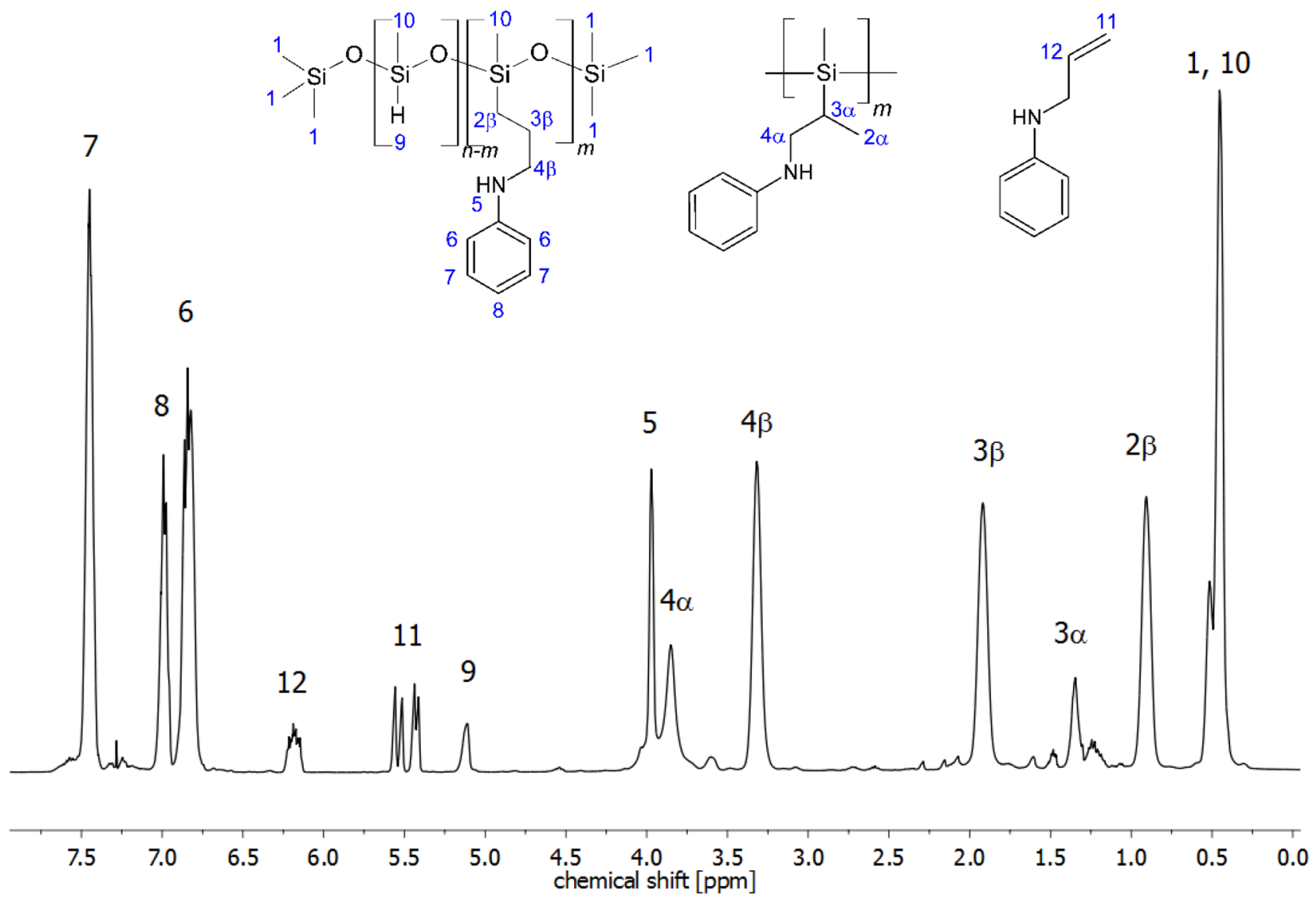

Fig. 4. ${ }^{1} \mathrm{H}$ NMR spectrum of PHMS_Naa_1.5 in $\mathrm{CDCl}_{3}$ 

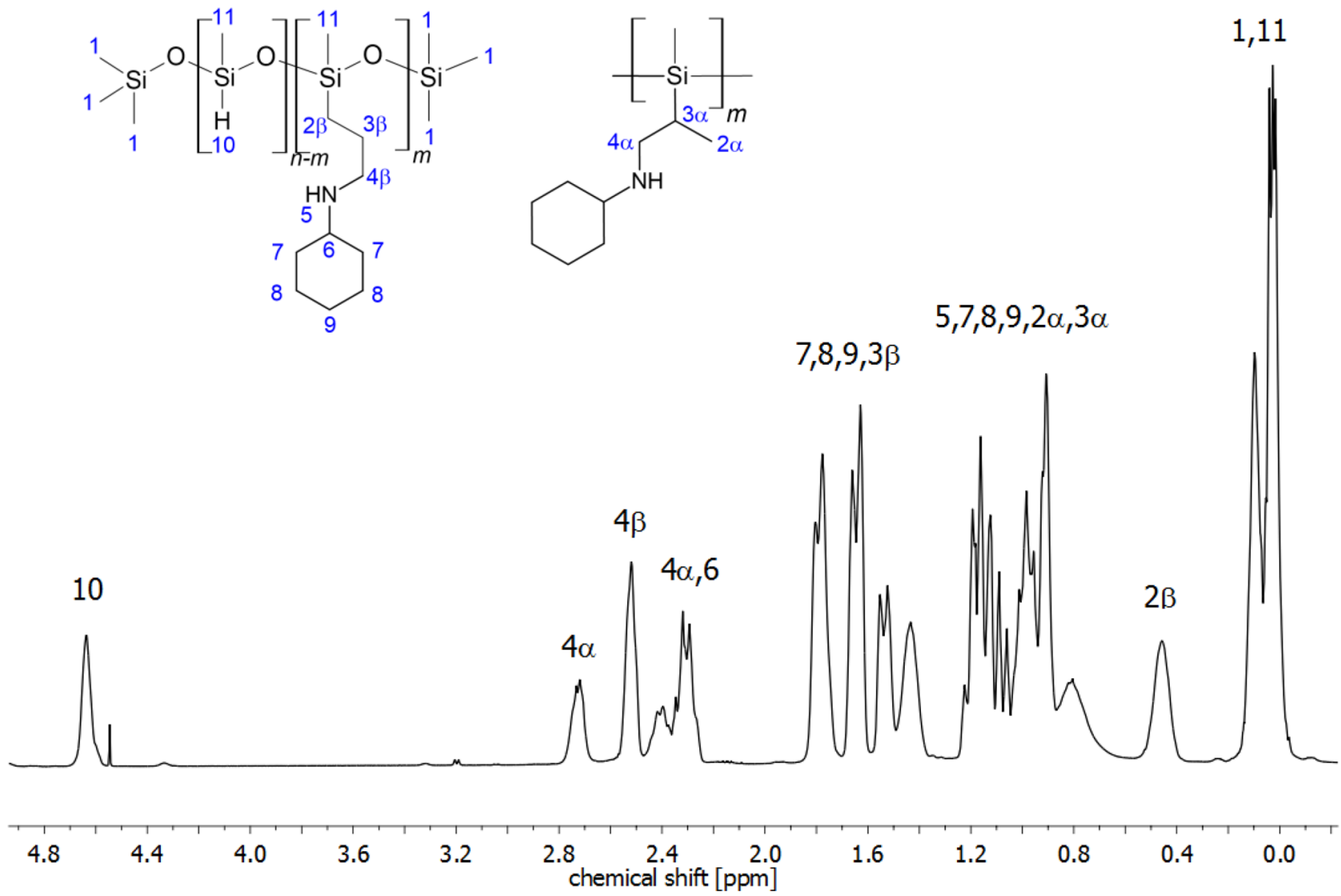

Fig. 5. ${ }^{1} \mathrm{H}$ NMR spectrum of PHMS_Nach_1.5 in $\mathrm{CDCl}_{3}$

increased correlation time of the higher molecular weight entities [43].

As can be seen in all spectra, signals of the $\mathrm{H} 2 \beta, \mathrm{H} 3 \beta$ and H4 $\beta$ protons at $\delta=0.88,1.89,3.29$ ppm (PHMS_Naa_1.5, Fig. 4), $\delta=0.46,1.43-1.80,4.52$ ppm (PHMS_Nach_1.5, Fig. 5) and $\delta=0.39,1.33-1.48,2.18$ ppm (PHMS_Nap_1.5 and PHMS_Nap_0.5, Fig. 6) prove that $\beta$-products (Fig. 1) are formed in the hydrosilylation of Naa, Nach and Nap with PHMS.

Importantly, in the proton spectra of the samples, signals ascribed to the $\alpha$-products (Fig. 1) are also detected. The signals of the $\mathrm{H} 3 \alpha, \mathrm{H} 4 \alpha$ protons are visible at $\delta=1.32$, 3.83 ppm (PHMS_Naa_1.5, Fig. 4), $\delta=0.80-1.22,2.73$ and 2.32 (PHMS_Nach_1.5, Fig. 5) and $\delta=1.33-1.48$, 2.72 ppm (PHMS_Nap_1.5 and PHMS_Nap_0.5, Fig. 6). The signals of the $\mathrm{H} 2 \alpha$ protons are clearly visible in the spectra of PHMS_Nach_1.5 $(\delta=0.81-1.19$ ppm, Fig. 5), PHMS_Nap_1.5 and PHMS_Nap_0.5 ( $\delta=0.87$ ppm, Fig. 6) while in the spectrum of PHMS_Naa_1.5 (Fig. 4) this signal is not distinguished probably because of low intensity. Lower intensities of the signals ascribed to the $\alpha$-products in all the spectra (Fig. 4-6) than the signals assigned to protons in $\beta$-products indicate that the $\beta$-products (antiMarkovnikov's) were formed predominantly in hydrosilylation of $N$-allyl amines with PHMS. Integration values of the signals due to the $\mathrm{H} 2 \beta$ and $\mathrm{H} 4 \alpha$ protons (selected for quantitative analysis because they are well resolved in the spectra and each of them corresponds to two protons, Fig. 4, Fig. 6) in the ${ }^{1} \mathrm{H}$ NMR spectra showed that molar ratios of $\beta$ to $\alpha$ isomers were equal to $2 / 1,2 / 0.17$ and 2/0.14 for PHMS_ Naa_1.5, PHMS_Nap_1.5 and PHMS_Nap_0.5, respectively (Table 1). This means that the $\beta$ adduct constituted ca. 67, 93 and 92 mol \% in the respective product mixtures. Unfortunately, the ${ }^{1} \mathrm{H}$ NMR spectrum of PHMS_Nach_1.5 (Fig. 5) was complex. Strict determination of the $\beta / \alpha$ isomer molar ratio was not possible in this case because of coincidence of the $\mathrm{H} \beta$ and $\mathrm{H} \alpha$ signals resulting in the lack of well separated signals ascribed to the $\alpha$-isomer.

Thus, NMR analysis clearly shows that hydrosilylation reactions of Naa, Nach and Nap with PHMS lead both to the $\beta$ and $\alpha$-products, however $\beta$ addition prevails. It is worth mentioning here that hydrosilylation of Naa and Nap with $\mathrm{M}_{2}{ }^{\mathrm{H}}$ was very selective: it led exclusively to the $\beta$ product. Only in the case of Nach, $\alpha$ addition also took place [36]. 
Fig. 6. ${ }^{1} \mathrm{H}$ NMR spectra in $\mathrm{CDCl}_{3}:$ a PHMS_Nap_1.5, b PHMS_Nap_0.5
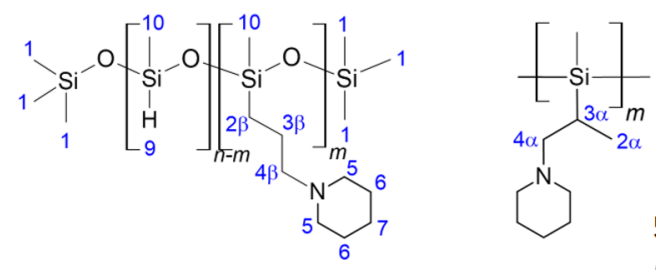

1,10

a)

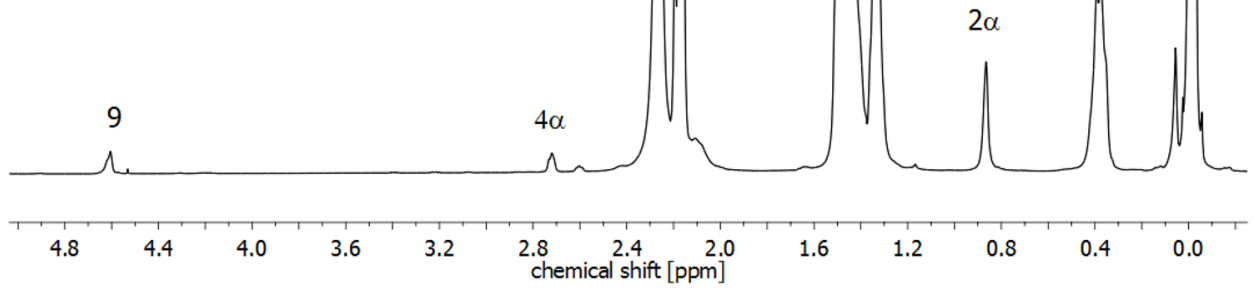

1,10

$3 \beta, 3 \alpha, 6,7$

b)

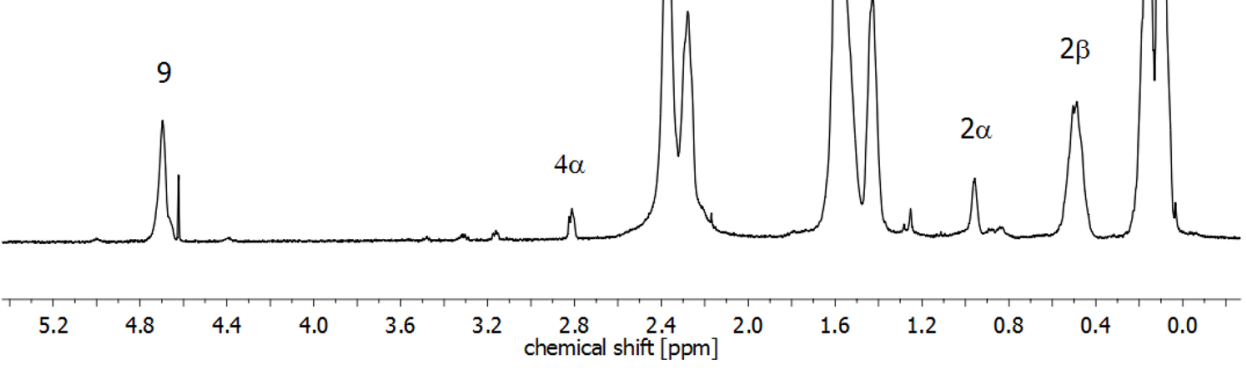

Thus, hydrosilylation of $\mathrm{N}$-allyl amines with the polymer are less regioselective than analogous reactions with a small molecule of $\mathrm{M}_{2}{ }^{\mathrm{H}}$.

${ }^{1} \mathrm{H}$ NMR-like FTIR-spectra of PHMS functionalized by all studied $N$-allyl amines contain the signals of protons in $\mathrm{Si}-\mathrm{H}$ groups $(\delta=\sim 4.8 \mathrm{ppm}$ [44]) which corroborates partial functionalization of the polymer. In the spectra of PHMS_Nap_1.5 and PHMS_Nap_0.5 the difference in intensity of this signal (proton H9, Fig. 6a, b) is clearly visible. In the case of the sample prepared with the excess of amine the intensity of the signal is lower than in the case when the deficient amount of Nap was used in the process. This finding is also in accordance with FTIR results.
The ${ }^{1} \mathrm{H}$ NMR spectrum of PHMS_Naa_1.5 (Fig. 4) contains characteristic signals at $\delta=5.54,5.42$ and $6.17 \mathrm{ppm}$ corresponding to protons of the allyl group in Naa (H11 and H12). The presence of these signals in the spectrum indicates contamination of the sample with unreacted Naa. The signals assigned to allyl groups are not observed in the spectra of the other investigated systems. Thus, the separation of the functionalized polymer from the unreacted $N$-allylamine was insufficient only in the case of PHMS_Naa_1.5.

Chemical structure of the obtained samples has been also investigated by ${ }^{29} \mathrm{Si}$ NMR (liquid samples) and ${ }^{29} \mathrm{Si} \mathrm{MAS}$ NMR (solid samples) spectroscopy. All the spectra of the final products (Fig. 7) show the signals in the ranges of -22.6 
Table 1 Results of ${ }^{1} \mathrm{H}$ NMR, ${ }^{29} \mathrm{Si}$ NMR and ${ }^{29} \mathrm{Si}$ MAS-NMR spectra analysis

\begin{tabular}{|c|c|c|c|c|c|c|}
\hline \multirow[t]{2}{*}{ Sample } & \multicolumn{3}{|l|}{${ }^{1} \mathrm{H}$ NMR } & \multicolumn{3}{|l|}{$\begin{array}{l}{ }^{29} \mathrm{Si} \mathrm{NMR} \text { and }{ }^{29} \mathrm{Si} \\
\text { MAS-NMR }\end{array}$} \\
\hline & Proton $^{\mathbf{a}}$ & $\delta[\mathrm{ppm}]$ & Integration & Unit & $\delta[\mathrm{ppm}]$ & $\begin{array}{l}\text { Relative contribution of } \\
\text { each signal in the spectrum } \\
{[\%]}\end{array}$ \\
\hline \multirow[t]{4}{*}{ PHMS_Naa_0.5 } & $-\mathbf{b}$ & & & $\mathrm{D}$ & -21.0 & 45 \\
\hline & & & & $\mathrm{D}^{\mathrm{H}}$ & -34.5 & 23 \\
\hline & & & & & -38.5 & 23 \\
\hline & & & & $\mathrm{T}$ & -66.0 & 9 \\
\hline \multirow[t]{5}{*}{ PHMS_Naa_1.5 } & $\mathrm{H} 2 \beta$ & 0.88 & $2 \mathrm{H}$ & $\mathrm{D}$ & -19.2 & 9 \\
\hline & & & & & -20.6 & 22 \\
\hline & $\mathrm{H} 4 \alpha$ & 3.83 & $1 \mathrm{H}$ & & -21.9 & 41 \\
\hline & & & & $\mathrm{D}^{\mathrm{H}}$ & -35.8 & 10 \\
\hline & & & & & -36.7 & 18 \\
\hline \multirow[t]{4}{*}{ PHMS_Nach_0.5 } & $-\mathbf{b}$ & & & $\mathrm{D}$ & -20.8 & 37 \\
\hline & & & & $\mathrm{D}^{\mathrm{H}}$ & -34.9 & 29 \\
\hline & & & & & -39.0 & 23 \\
\hline & & & & $\mathrm{T}$ & -65.7 & 11 \\
\hline \multirow[t]{2}{*}{ PHMS_Nach_1.5 } & $\mathrm{H} 2 \beta$ & 0.46 & $2 \mathrm{H}$ & $\mathrm{D}$ & -21.5 & $67^{d}$ \\
\hline & $\mathrm{H} 4 \alpha$ & $\begin{array}{l}2.73, \\
2.42-2.22\end{array}$ & $-c$ & $\mathrm{D}^{\mathrm{H}}$ & -37.5 & $33^{d}$ \\
\hline \multirow[t]{4}{*}{ PHMS_Nap_0.5 } & $\mathrm{H} 2 \beta$ & 0.40 & $2 \mathrm{H}$ & $\mathrm{D}$ & -20.6 & 45 \\
\hline & & & & $\mathrm{D}^{\mathrm{H}}$ & -34.8 & 22 \\
\hline & $\mathrm{H} 4 \alpha$ & 2.72 & $0.14 \mathrm{H}$ & & -38.9 & 23 \\
\hline & & & & $\mathrm{T}$ & -65.8 & 10 \\
\hline \multirow[t]{3}{*}{ PHMS_Nap_1.5 } & $\mathrm{H} 2 \beta$ & 0.39 & $2 \mathrm{H}$ & $\mathrm{D}$ & -21.3 & 28 \\
\hline & & & & & -22.6 & 58 \\
\hline & $\mathrm{H} 4 \alpha$ & 2.72 & $0.17 \mathrm{H}$ & $\mathrm{D}^{\mathrm{H}}$ & -37.8 & 14 \\
\hline
\end{tabular}

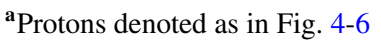

${ }^{\mathbf{b} 1} \mathrm{H}$ NMR spectra were measured for liquid samples only

${ }^{\mathbf{c}}$ A great number of overlapping lines in this region of the spectrum (Fig. 5) hinder accurate signal integration

${ }^{\mathbf{d}}$ The result may not be accurate due to poor spectrum quality

to $-19.2 \mathrm{ppm}$ and -38.5 to $-32.2 \mathrm{ppm}$. Moreover, in the spectra of the samples prepared using the deficient amount of the amine ( $\mathrm{Si}-\mathrm{H}: \mathrm{CH}_{2}=\mathrm{CH}-\mathrm{CH}_{2}$ - equal to 1:0.5), additional signal at about -66.0 ppm occurs (Fig. 7).

The signals in the range of -22.6 to -19.2 ppm can be ascribed to the $\left[\mathrm{SiO}_{2}\left(\mathrm{CH}_{3}\right)\left(\mathrm{CH}_{2} \mathrm{CH}_{2} \mathrm{CH}_{2}\right)\right]$ units since they are located in the region characteristic for the $\mathrm{D}$ (i.e. $\left.\left[\mathrm{SiO}_{2} \mathrm{C}_{2}\right]\right)$ units occurring in linear polysiloxanes $(-20.5$ to $-22.0 \mathrm{ppm}$ [45]). This is a further proof that functionalization of PHMS by Naa, Nach and Nap does occur in the studied systems. It should be noted that in this spectral region, in the case of liquid samples, three (PHMS_Naa_1.5) or two (PHMS_Nap_1.5) separated signals occur (Fig. 7, Table 1). Because of the poor quality of the spectrum of PHMS_Nach_1.5 (Fig. 7), which was also a liquid sample, signal due to D units is broad and has low intensity. The shape of the signal indicates, however, that it is composed of several lines. Broad and complex signals originating from
D units in the ${ }^{29} \mathrm{Si}$ MAS-NMR spectra of solid samples (PHMS_Naa_0.5; PHMS_Nach_0.5; PHMS_Nap_0.5) are also observed. Thus, it can be assumed that the presence of several signals and their complexity in the range corresponding to D units in the spectra of liquid and solid products of PHMS modified with $N$-allyl compounds, is due to the existence of $\alpha$ and $\beta$ linkages in different chemical environment in the polymer structure. This is consistent with the results of the ${ }^{1} \mathrm{H}$ NMR analysis of liquid products of PHMS functionalization and also with our previously reported results concerning functionalization of $\mathrm{M}_{2}{ }^{\mathrm{H}}$ by Nach [36]. The ${ }^{29} \mathrm{Si}$ NMR measurements prove, however, that during modification of the polymer with $N$-allyl compounds, both $\alpha$ and $\beta$ linkages are formed in all studied systems.

Additionally, ${ }^{29} \mathrm{Si}$ NMR spectroscopy, like other spectroscopic methods, clearly shows that functionalization of PHMS in our systems was not complete and in the polymer chain unreacted $\mathrm{Si}-\mathrm{H}$ groups still remained after 


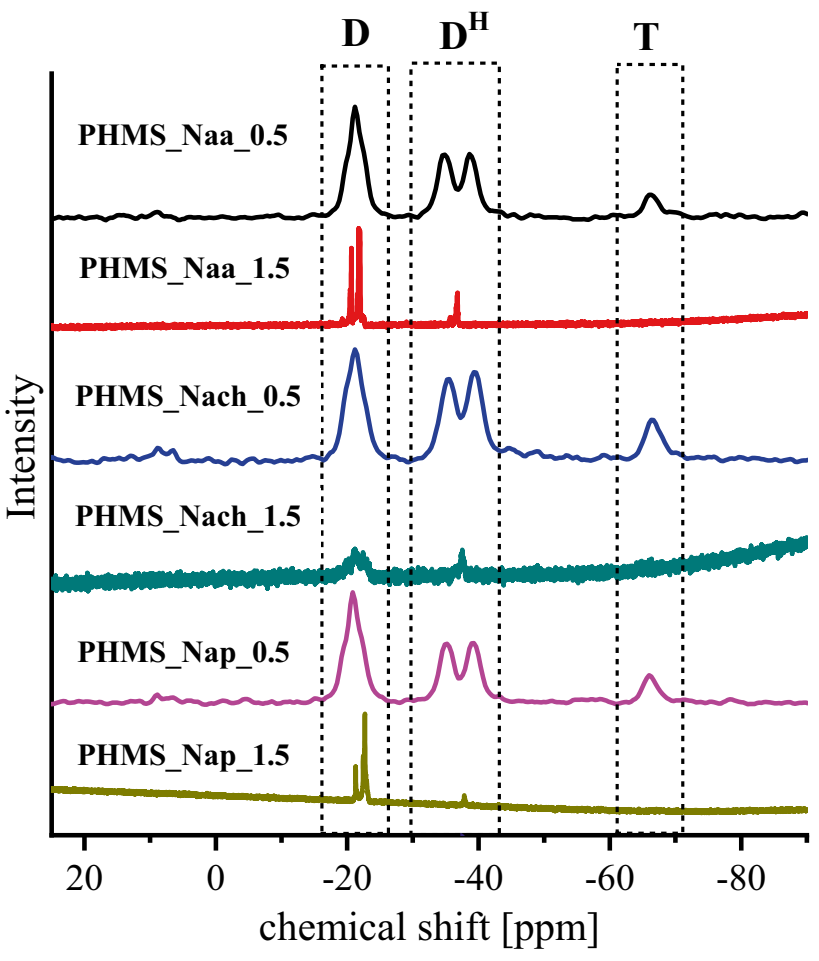

Fig. $7{ }^{29} \mathrm{Si}$ NMR (samples PHMS_Naa_1.5; PHMS_Nach_1.5; PHMS_Nap_1.5) and ${ }^{29} \mathrm{Si}$ MAS-NMR spectra (samples PHMS_ Naa_0.5; PHMS_Nach_0.5; PHMS_Nap_0.5) of PHMS functionalized with $N$-allyl compounds

hydrosilylation; in the spectra the broad signals in the range of -38.5 to $-32.2 \mathrm{ppm}$ associated with the $\mathrm{Si}$ units containing $\mathrm{H}$ atoms $\left[\mathrm{SiO}_{2}\left(\mathrm{CH}_{3}\right) \mathrm{H}\right]$, referred to as $\mathrm{D}^{\mathrm{H}}$ (Fig. 7, Table 1), in different chemical environments, are observed [45].

${ }^{29} \mathrm{Si}$ MAS-NMR spectra also contain the signal at about $-66.0 \mathrm{ppm}$ related to the presence of the $\mathrm{T}\left(\left[\mathrm{SiO}_{3} \mathrm{C}\right]\right)$ units in the polymer structure (Fig. 7) [45]. The fact that these signals are visible only in the spectra of solid, insoluble samples (prepared during the reaction of PHMS with $N$-allyl amines at molar ratio of $\mathrm{Si}-\mathrm{H}: \mathrm{CH}_{2}=\mathrm{CH}-\mathrm{CH}_{2}$ - groups equal to 1:0.5), unambiguously confirms, postulated previously, crosslinking of the polymer caused by the condensation of $\mathrm{Si}-\mathrm{OH}$ groups, resulting from hydrolysis of a part of a large number of $\mathrm{Si}-\mathrm{H}$ groups in these systems.

According to quantitative analysis of ${ }^{29} \mathrm{Si}$ NMR spectra, relative contributions of the signals of $\mathrm{D}$ units, originating in the investigated systems from hydrosilylation of $\mathrm{N}$-allyl compounds with PHMS, constitute 37\% for PHMS_Nach_0.5 and 45\% for PHMS_Naa_0.5 and PHMS_Nap_0.5, respectively (Table 1). The relative contributions of the signals of $\mathrm{D}$ units in the spectra of the samples obtained with the excess of the $\mathrm{N}$-allyl compounds are significantly higher: $72 \%$ and 86\% for PHMS_Naa_1.5 and PHMS_Nap_1.5, respectively (Table 1). This means that the degrees of polymer functionalization in these samples are higher. Simultaneously,
Table 2 Results of elemental analysis of PHMS functionalized by $\mathrm{N}$-allyl compounds

\begin{tabular}{|c|c|c|c|c|c|}
\hline \multirow[t]{3}{*}{ Sample } & \multirow{2}{*}{\multicolumn{2}{|c|}{$\begin{array}{l}\text { Contents } \\
\text { of elements } \\
\text { [wt.\%] } \\
\mathrm{N}\end{array}$}} & \multirow{3}{*}{$\mathrm{C}$} & \multirow{3}{*}{$\mathrm{H}$} & \multirow{3}{*}{$\mathrm{SiO}^{\mathrm{c}}$} \\
\hline & & & & & \\
\hline & calc. $^{\mathbf{a}}$ & found $^{\mathbf{b}}$ & & & \\
\hline PHMS_Naa_0.5 & 5.42 & $\begin{array}{r}5.17 \\
(95.4)\end{array}$ & 50.60 & 7.71 & 36.52 \\
\hline PHMS _Naa_1.5 & $\begin{array}{c}7.15 \\
(8.70)\end{array}$ & $\begin{array}{r}6.84 \\
(95.7)\end{array}$ & 56.86 & 9.94 & 26.36 \\
\hline PHMS _Nach_0.5 & 5.30 & $\begin{array}{r}4.53 \\
(85.5)\end{array}$ & 46.76 & 9.93 & 38.78 \\
\hline PHMS _Nach_1.5 & $\begin{array}{c}6.94 \\
(8.24)\end{array}$ & $\begin{array}{r}4.95 \\
(71.3)\end{array}$ & 48.30 & 10.13 & 36.62 \\
\hline PHMS _Nap_0.5 & 5.60 & $\begin{array}{r}5.87 \\
(104.8)\end{array}$ & 47.79 & 12.61 & 33.73 \\
\hline PHMS _Nap_1.5 & $\begin{array}{c}7.45 \\
(9.15)\end{array}$ & $\begin{array}{r}7.50 \\
(100.7)\end{array}$ & 55.31 & 12.57 & 24.62 \\
\hline
\end{tabular}

a Without brackets-the maximum possible nitrogen content [\%] resulting from the stoichiometry of the reaction are given; in brackets - resulting from the amount of the $N$-allyl compound used in the reaction;

${ }^{\mathbf{b}}$ In brackets fractions of $\mathrm{N}$ incorporated into the polymer, calculated as $\left(\mathrm{N}_{\text {found }} / \mathrm{N}_{\text {calc. }}\right) \cdot 100 \%$ are given;

c $\% \mathrm{SiO}=100 \%-\Sigma \% \mathrm{C}, \% \mathrm{H}, \% \mathrm{~N}$

in the spectra of the systems obtained at the molar ratio of $\mathrm{Si}-\mathrm{H}: \mathrm{CH}_{2}=\mathrm{CH}-\mathrm{CH}_{2^{-}}$groups equal to $1: 1.5$, the relative contributions of $\mathrm{D}^{\mathrm{H}}$ units are lower (28\%-PHMS_Naa_1.5 and 14\%-PHMS_Nap_1.5, Table 1) than in the spectra of the samples obtained at the molar ratio of $\mathrm{Si}-\mathrm{H}: \mathrm{CH}_{2}=\mathrm{CH}-\mathrm{CH}_{2}-$ equal to 1:0.5 (46\%-PHMS_Naa_0.5, 52\%-PHMS_Nach_0.5 and 46\%-PHMS_Nap_0.5, Table 1), which clearly shows that the samples obtained with the deficiency of the $\mathrm{N}$-allyl compound contained higher amounts of unreacted $\mathrm{Si}-\mathrm{H}$ groups than those obtained with its excess. These findings are fully consistent with the results of FTIR studies.

Moreover, the relative contributions of $T$ units in the ${ }^{29}$ Si MAS-NMR spectra of the samples obtained using deficient amounts of amines, are relatively low-equal to $9-11 \%$ (Table 1). This indicates that in these systems crosslinking of PHMS accompanying the hydrosilylation process occurred to a low degree.

Elemental analysis proved that moieties originating from $N$-allyl amines (Naa, Nach and Nap) were introduced into the polymer chain. All the samples contained nitrogen (Table 2). As expected, the amount of nitrogen introduced into PHMS increased with increasing amount of the $\mathrm{N}$-allyl compound used in the reaction. However, considering the obvious discrepancies observed for the samples modified by Nap (overestimated nitrogen contents, Table 2) and the presence of unreacted Naa in the final PHMS_Naa_1.5 sample, 
which was proven by ${ }^{1} \mathrm{H}$ NMR studies, the elemental analysis results should be interpreted with caution.

To summarize, results of the conducted experiments show that direct hydrosilylation of $\mathrm{N}$-allyl amines with PHMS in the presence of a Pt catalyst is possible. Functionalization, however, in all the systems is not complete; after the reaction unreacted $\mathrm{Si}-\mathrm{H}$ groups still exist in the polymer structure even if the excess of $N$-allyl compound is used. For the samples with higher amount of unreacted $\mathrm{Si}-\mathrm{H}$ groups crosslinking of the polymer is observed. It should be noted that the applied $N$-allyl amines differed in nucleophicity and molecular structure [36]. Their influence on reactivity of these compounds in hydrosilylation reaction with PHMS appears to be rather complex. The reactions with Nap result in the highest conversion degrees of the $\mathrm{Si}-\mathrm{H}$ groups as related to the reactions with Naa and Nach in the corresponding systems. Polymer functionalization degrees with Nap moieties, established on the basis of ${ }^{29} \mathrm{Si}$ NMR spectroscopy, are also higher. Therefore our investigations suggest that the structure of this molecule is more advantageous for hydrosilylation than the structure of Naa and Nach. To explain this finding a separate study should be conducted. Moreover, NMR analysis clearly showed that hydrosilylation reactions of Naa, Nach and Nap with PHMS lead both, to the $\beta$ and $\alpha$ addition products, however the $\beta$ addition prevails.

\section{Functionalization of PHMS with (4VP)}

Our previously reported results concerning functionalization of $\mathrm{M}_{2}{ }^{\mathrm{H}}$ by $4 \mathrm{VP}$ showed that the reaction does not take place in the studied conditions $\left(60{ }^{\circ} \mathrm{C}\right.$, toluene, $\left.24 \mathrm{~h}\right)$ [36]. We decided, however, to verify whether the hydrosilylation of $4 \mathrm{VP}$ with a polymeric compound, PHMS occurs as there are reports showing that $4 \mathrm{VP}$ can be hydrosilylated by a macromolecular compound, PHMS-DMS copolymer, in the presence of Karstedt's catalyst [34, 35]. We changed reaction conditions with respect to those applied in the functionalization of PHMS by $\mathrm{N}$-allyl compounds: the temperature of the process was raised to $110^{\circ} \mathrm{C}$ (similar to that used in Ref. $[34,35])$, reactions were conducted with and without the solvent (toluene), at four different $\mathrm{Si}-\mathrm{H}: \mathrm{CH}_{2}=\mathrm{CH}$ - groups molar ratios equal to $1: 1.5 ; 1: 1 ; 1: 0.5$ or $1: 0.25$ (Experimental Section). All these changes were aimed at getting conclusive results.

During treatment of PHMS with 4VP, similarly to the reactions of the polymer with $N$-allyl amines, FTIR spectra of the reaction mixtures were measured. It was found that regardless of the molar ratio of $\mathrm{Si}-\mathrm{H}: \mathrm{CH}_{2}=\mathrm{CH}$ - groups, and regardless of whether the process is carried out with or without the solvent, the intensity of the band at $2169 \mathrm{~cm}^{-1}$, ascribed to the $\mathrm{Si}-\mathrm{H}$ stretching vibrations [37], decreases over time (Fig. 8). These changes, however, are not as
Table 3 Conversion degrees of $\mathrm{Si}-\mathrm{H}$ groups in the reactions of PHMS with 4VP evaluated by FTIR spectra analysis

\begin{tabular}{lll}
\hline Sample & $\begin{array}{l}\text { Conversion degree of the } \\
\text { Si-H groups [\%] }\end{array}$ & \\
& Solvent conditions & $\begin{array}{l}\text { Solvent- } \\
\text { free condi- } \\
\text { tions }\end{array}$ \\
\hline PHMS_4VP_1.5 & 34.6 & 34.7 \\
PHMS_4VP_1 & 27.9 & 32.6 \\
PHMS_4VP_0.5 & 25.9 & 16.2 \\
PHMS_4VP_0.25 & 23.3 & 12.1 \\
\hline
\end{tabular}

a Estimated by comparing the ratios of integral intensities of $\mathrm{Si}-\mathrm{H}$ (at $2169 \mathrm{~cm}^{-1}$ ) and $\mathrm{Si}_{-} \mathrm{CH}_{3}\left(\right.$ at $\left.1262 \mathrm{~cm}^{-1}\right)$ bands in the FTIR spectra of PHMS and final reaction mixtures

significant as in the case of modification of PHMS with $N$-allyl compounds (Fig. 2). This suggests that after the reactions in the PHMS_4VP systems, significant amounts of unreacted $\mathrm{Si}-\mathrm{H}$ groups remain in the polymer.

The final conversion degrees of $\mathrm{Si}-\mathrm{H}$ groups calculated based on FTIR spectra for all the investigated systems (Table 3) depend on the molar ratio of the reactants used. Quite expectedly for polymer functionalization, they decrease with the reduction in the amount of 4VP applied in the reaction. However, the influence of the solvent on the $\mathrm{Si}-\mathrm{H}$ groups conversion degrees is not systematic. It does not affect transformations of these groups in the PHMS_4VP_1.5 system as their conversion degrees are the same for the reactions performed with and without the solvent $(\sim 34.6 \%)$. In contrast, for PHMS_4VP_1 the $\mathrm{Si}-\mathrm{H}$ groups are converted to higher extent for the reaction conducted in the non-solvent conditions. In the remaining systems, higher degrees of conversion of $\mathrm{Si}-\mathrm{H}$ groups are observed in the case of syntheses carried out in the solvent than without it. For PHMS_4VP_0.25 the difference is the most significant. This suggests that in the reaction media with lower amounts of 4VP (PHMS_4VP_0.25 and PHMS_4VP_0.5) the presence of toluene is beneficial for the transformations of $\mathrm{Si}-\mathrm{H}$ groups. In the reactions performed with higher amounts of 4VP (PHMS_4VP_1 and PHMS_4VP_1.5), the role of pyridine on the reaction course seems to be crucial.

Considering the solid form of all final reaction products (Experimental Section), and taking into account that for the solid samples of PHMS functionalized with $\mathrm{N}$-allyl compounds ${ }^{29} \mathrm{Si}$ MAS-NMR spectroscopy proved crosslinking of the polymer by condensation of silanol groups, it could be supposed that in the PHMS_4VP systems $\mathrm{Si}-\mathrm{OH}$ groups were formed as well. Most probably, they resulted from hydrolysis of $\mathrm{Si}-\mathrm{H}$ groups present in the polymer caused by water existing in 4VP and/or the solvent (despite their drying before the reactions). Based on quantitative FTIR 
Table 4 Results of elemental analysis of the final, purified samples of PHMS functionalized by 4VP

\begin{tabular}{|c|c|c|c|c|c|c|c|c|c|c|c|}
\hline \multirow[t]{3}{*}{$\begin{array}{l}\text { PHMS_4VP } \\
\text { solvent system }\end{array}$} & \multicolumn{5}{|c|}{$\begin{array}{l}\text { Contents of ele- } \\
\text { ments [wt.\%] }\end{array}$} & \multirow[t]{3}{*}{$\begin{array}{l}\text { PHMS_4VP } \\
\text { solvent-free } \\
\text { system }\end{array}$} & \multicolumn{5}{|c|}{$\begin{array}{l}\text { Contents of ele- } \\
\text { ments [wt.\%] }\end{array}$} \\
\hline & $\mathrm{N}$ & & $\mathrm{C}$ & $\mathrm{H}$ & $\mathrm{SiO}^{\mathrm{c}}$ & & $\mathrm{N}$ & & $\mathrm{C}$ & $\mathrm{H}$ & $\mathrm{SiO}^{\mathrm{c}}$ \\
\hline & calc. $^{\mathbf{a}}$ & found $^{\mathbf{b}}$ & & & & & calc. $^{\mathbf{a}}$ & found $^{\mathbf{b}}$ & & & \\
\hline 1.5 & $8.35(9.54)$ & $\begin{array}{l}3.63 \\
(43.5)\end{array}$ & 34.62 & 5.58 & 56.18 & 1.5 & $8.35(9.54)$ & $\begin{array}{l}9.03 \\
(108.1)\end{array}$ & 68.36 & 6.64 & 15.97 \\
\hline 1 & 8.35 & $\begin{array}{l}1.67 \\
(20.0)\end{array}$ & 25.84 & 6.13 & 66.36 & 1 & 8.35 & $\begin{array}{l}1.28 \\
(15.3)\end{array}$ & 20.97 & 5.49 & 72.26 \\
\hline 0.5 & 6.08 & $\begin{array}{l}1.26 \\
(20.7)\end{array}$ & 28.15 & 6.17 & 64.42 & 0.5 & 6.08 & $\begin{array}{l}3.11 \\
(51.2)\end{array}$ & 33.99 & 6.05 & 56.85 \\
\hline 0.25 & 3.94 & $\begin{array}{l}0.79 \\
(20.1)\end{array}$ & 23.39 & 6.55 & 69.28 & 0.25 & 3.94 & $\begin{array}{l}1.07 \\
(27.2)\end{array}$ & 20.21 & 4.07 & 74.66 \\
\hline
\end{tabular}

${ }^{\text {a }}$ Without brackets-the maximum possible nitrogen content [\%] resulting from the stoichiometry of the reaction are given; in brackets-resulting from the amount of the 4VP in the reaction;

${ }^{b}$ In brackets fractions of $\mathrm{N}$ incorporated into the polymer, calculated as $\left(\mathrm{N}_{\text {found }} / \mathrm{N}_{\text {calc }}\right) \cdot 100 \%$ are given;

c $\% \mathrm{SiO} 100 \%-\Sigma \% \mathrm{C}, \% \mathrm{H}, \% \mathrm{~N}$. In order to draw final conclusions on the reactions proceeding in the PHMS_4VP systems, the obtained, purified PHMS_4VP samples were subjected to FTIR and ${ }^{29}$ Si MAS-NMR investigations

spectra analysis (Table 3) it can be assumed that the conversion of $\mathrm{Si}-\mathrm{H}$ groups during the processes carried out in toluene in the PHMS_4VP_0.25 and PHMS_4VP_0.5 systems, with lower amounts of $4 \mathrm{VP}$ with respect to the polymer, water contained in the solvent was the predominant cause of hydrolysis. This is suggested by higher conversion degrees of $\mathrm{Si}-\mathrm{H}$ groups in both systems when the reactions were performed in toluene. For the processes conducted with larger amounts of $4 \mathrm{VP}$, in turn, hydrolysis seems to be related mainly to water contained in $4 \mathrm{VP}$ since $\mathrm{Si}-\mathrm{H}$ groups transformed to a higher degree in the solvent-free medium (PHMS_4VP_1 system) or the presence of toluene did not affect their conversion degree (PHMS_4VP_1.5 system).

Moreover, quantitative FTIR spectra analysis shows that conversion degrees of $\mathrm{Si}-\mathrm{H}$ groups in the PHMS_4VP systems are markedly lower than those found for systems with $N$-allyl compounds. This indicates that, if functionalization of PHMS with 4VP occurs, then to a low extent.

According to elemental analysis, all the obtained samples contained nitrogen (Table 4). Importantly, its content decreased after extraction of the samples with toluene in a Soxhlet apparatus (results not shown), which indicates the presence of unreacted 4VP in the crude reaction products, removed during the purification process (Experimental Section). In the final, purified samples obtained in toluene, nitrogen content decreased as the amount of 4VP used in the reaction was reduced (Table 4). This is what was expected for polymer functionalization and agrees with FTIR results which showed lowering in the conversion degrees of $\mathrm{Si}-\mathrm{H}$ groups as the amount of 4VP in the systems decreased
Fig. 8 FTIR spectra showing the decrease of the $\mathrm{Si}-\mathrm{H}$ stretching vibrational band during preparation of $\mathbf{a}$ PHMS_4VP_1.5 sample and $\mathbf{b}$ PHMS_4VP_0.25 sample, in toluene
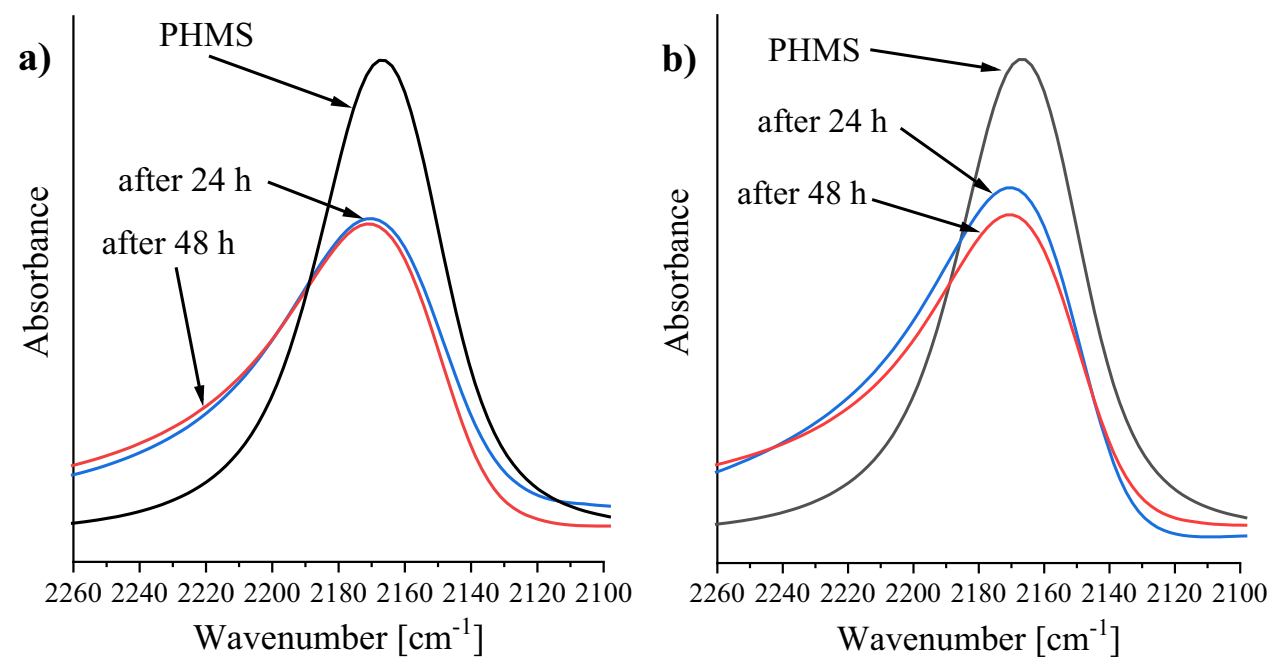
(Table 3). In the case of the samples obtained in solvent-free conditions, however, the results are not consistent. Excessive amount of nitrogen as compared to the maximum possible for the fully functionalized polymer $(108.1 \%)$ is observed for the PHMS_4VP_1.5 sample obtained in the solvent-free conditions (Table 4). This indicates the presence of unreacted 4VP in this sample which could not be excluded in the other ones, either. Removal of 4VP molecules located in the cross-linked polymer network might have been difficult. Hence, the presence of nitrogen in the studied systems does not prove that the moieties originating from $4 \mathrm{VP}$ were introduced into the polymer molecule, i.e. that hydrosilylation of 4VP by PHMS took place.

It is worth noting that the products of hydrosilylation of $N$-allyl compounds with PHMS contained higher amounts of nitrogen (4.53-5.87 wt.\% and 4.95-7.50 wt.\% for the molar ratios of $\mathrm{Si}-\mathrm{H}: \mathrm{CH}_{2}=\mathrm{CH}-\mathrm{CH}_{2}$ - equal to $1: 0.5$ and $1: 1.5$, respectively, Table 2) than found for PHMS treated with $4 \mathrm{VP}$ (1.26 wt.\% and $3.63 \mathrm{wt} . \%$ for the reaction in toluene with molar ratios of $\mathrm{Si}-\mathrm{H}: \mathrm{CH}_{2}=\mathrm{CH}$ - equal to $1: 0.5$ and $1: 1.5$, respectively, Table 4). Simultaneously, content of nitrogen in the 4VP molecule ( $13 \mathrm{wt} . \%$ ) is higher than those in $N$-allyl amines applied in the experiments (Nach: $11 \mathrm{wt} . \%$, Naa: 10 wt. \%, Nap: 11 wt.\%). Thus, lower contents of nitrogen in the materials obtained with 4VP confirm that incorporation of its moieties into the systems was lower than those of $N$-allyl compounds.

All FTIR spectra (Fig. 9) are dominated by the bands due to PHMS corresponding to: asymmetric stretching vibrations of Si-O-Si groups $\left(1130-1000 \mathrm{~cm}^{-1}\right)$, as well as, of $\mathrm{C}-\mathrm{H}$ bond in $\mathrm{Si}-\mathrm{CH}_{3}$ groups vibrations: symmetric bending $\left(1262 \mathrm{~cm}^{-1}\right)$ and symmetric $\left(2917 \mathrm{~cm}^{-1}\right)$ and asymmetric $\left(2967 \mathrm{~cm}^{-1}\right)$ stretching [37, 38, 42]. Moreover, in all the spectra the band at $2169 \mathrm{~cm}^{-1}$, ascribed to $\mathrm{Si}-\mathrm{H}$ stretching vibrations, is clearly visible. The presence of this band and its significant intensity show that the vast majority of $\mathrm{Si}-\mathrm{H}$ groups in the polymer remained unreacted, which was revealed by the quantitative analysis of FTIR spectra already discussed.

The bands indicating the presence of 4VP units exhibit generally low intensity in the FTIR spectra of the materials and occur at (Fig. 9): $2917 \mathrm{~cm}^{-1}$ (symmetric C-H stretching vibrations), $1599 \mathrm{~cm}^{-1}(\mathrm{C}=\mathrm{C}$ stretching vibrations in the aromatic ring), $1416 \mathrm{~cm}^{-1}$ (deformation vibrations of $=\mathrm{C}-\mathrm{H})$. The exception is the spectrum of PHMS_4VP_1.5-the reaction carried out without solvent (Fig. 9b), which contains intense bands originating from $4 \mathrm{VP}$ at $3401,3024,1599 \mathrm{~cm}^{-1}$ and a characteristic combination of bands and overtones in the range of 2000-1600 $\mathrm{cm}^{-1}$ [46]. In this spectrum, the band of low intensity at $1633 \mathrm{~cm}^{-1}$ due to stretching vibrations of $\mathrm{C}=\mathrm{C}$ bonds in unreacted vinyl groups, is also visible [37]. This confirms the results of elemental analysis which revealed the presence of unreacted 4VP in the PHMS_4VP_1.5 sample.

It should be noted that the bands at $2900-2850 \mathrm{~cm}^{-1}$ and $1140 \mathrm{~cm}^{-1}$ (C-H bonds vibrations: asymmetric stretching and deformation, respectively [37, 38, 42]) attributed to $-\mathrm{CH}_{2}$ - groups in ethylene bridges $\left(-\mathrm{CH}_{2} \mathrm{CH}_{2^{-}}\right)$at silicon atoms resulting from hydrosilylation (Fig. 9), do not appear in the spectra of the final systems. Thus, analysis of FTIR spectra of PHMS_4VP samples leads to the conclusion that functionalization of PHMS in none of the studied systems takes place.

The conclusions drawn from FTIR are fully corroborated by ${ }^{29} \mathrm{Si}$ MAS-NMR spectra (Fig. 10). We measured the spectra of selected samples: PHMS_4VP_1.5 and PHMS_4VP_0.25, obtained in toluene and solventfree conditions. The analysis of the data clearly shows that the hydrosilylation of 4VP by PHMS does not occur. The absence of the signals in the range of -20 to $-22 \mathrm{ppm}$
Fig. 9 FTIR spectra of the final, purified products of the reactions in the PHMS_4VP systems carried out in a solvent (toluene), b solvent-free conditions
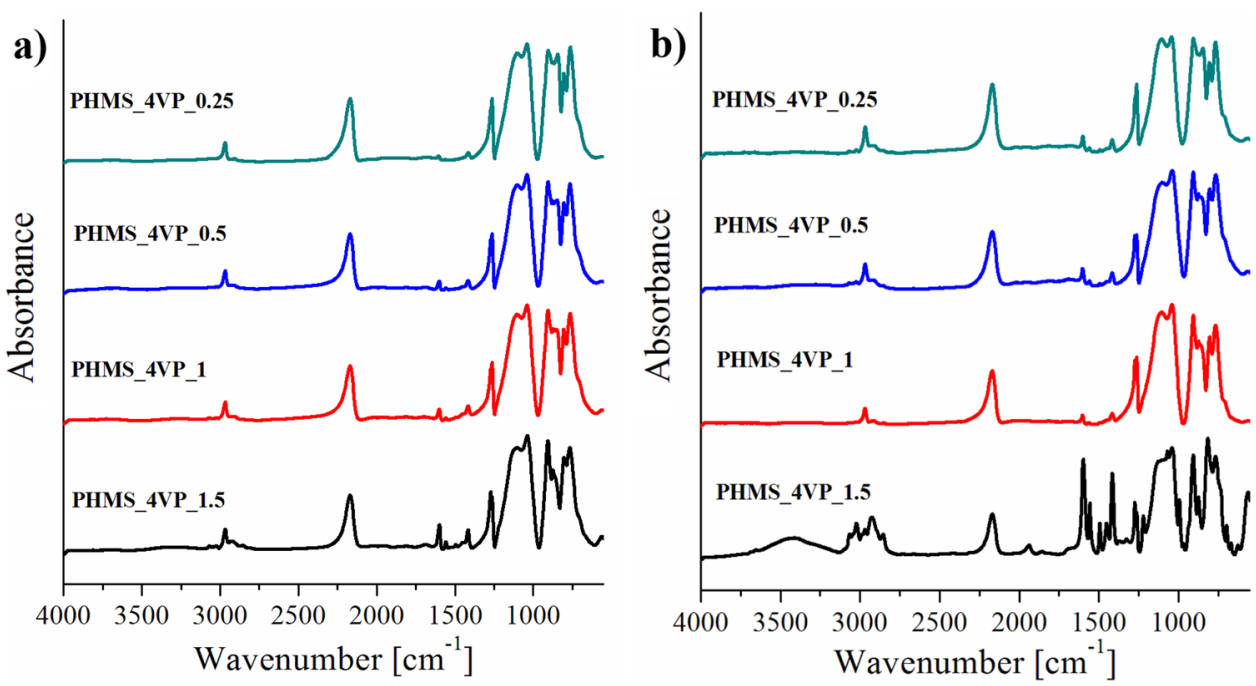


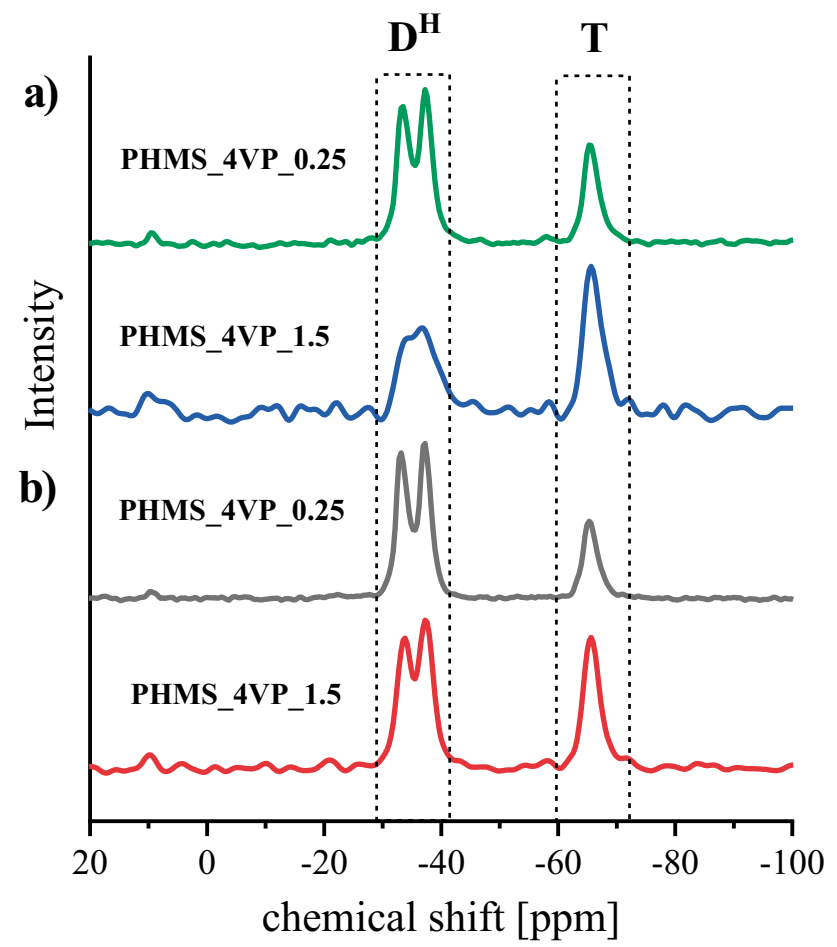

Fig. 10. ${ }^{29} \mathrm{Si}$ MAS-NMR spectra of PHMS treated with 4VP in: a solvent-free conditions, b solvent (toluene)

proves that no $-\mathrm{Si}-\mathrm{CH}_{2} \mathrm{CH}_{2}$ - or $-\mathrm{Si}-\mathrm{CH}\left(\mathrm{CH}_{3}\right)$ - moieties were formed during the reactions, which precludes successful hydrosilylation.

In all the spectra, however, the lines at -33.9 to $-37.1 \mathrm{ppm}$, ascribed to the $\mathrm{D}^{\mathrm{H}}$ units $\left[\mathrm{SiO}_{2}\left(\mathrm{CH}_{3}\right) \mathrm{H}\right]$ and at $~-65.0 \mathrm{ppm}$, related to the presence of the $\mathrm{T}$ units $\left(\left[\mathrm{SiO}_{3} \mathrm{C}\right]\right)$ in the polymer structure, are clearly visible [45]. Thus, ${ }^{29} \mathrm{Si}$ MASNMR spectroscopy unambiguously confirms the presence of unreacted $\mathrm{Si}-\mathrm{H}$ groups and polymer cross-linking resulting from partial hydrolysis of $\mathrm{Si}-\mathrm{H}$ groups of PHMS followed by condensation of silanol groups formed.

According to the quantitative analysis of ${ }^{29} \mathrm{Si}$ MAS-NMR spectra relative contributions of the signals of $\mathrm{D}^{\mathrm{H}}$ units constitute from 51 to $76 \%$ and those of T units - from 24 to $49 \%$ (Table 5). This shows that high amounts of $\mathrm{Si}-\mathrm{H}$ groups were left in the polymer after the reactions. The relative contributions of the signals of $\mathrm{T}$ units in the spectra of the samples obtained at the same molar ratios of $\mathrm{Si}-\mathrm{H}: \mathrm{CH}_{2}=\mathrm{CH}-$ groups, were higher for those obtained in the solvent while among the samples prepared in the same conditions (with or without solvent), more $\mathrm{T}$ units were formed in the systems with excess of 4VP (Table 5). These results show that hydrolysis of $\mathrm{Si}-\mathrm{H}$ groups occurring in the studied systems involved residual water from the chemicals used, both toluene and 4VP.
Table 5 Chemical shifts, assignments and relative contributions of signals in the ${ }^{29} \mathrm{Si}$ MAS-NMR spectra of PHMS_4VP_0.25 and PHMS_4VP_1.5 samples

\begin{tabular}{llll}
\hline Sample & Unit & $\delta$ [ppm] & $\begin{array}{l}\text { Relative } \\
\text { contribution } \\
{[\%]}\end{array}$ \\
\hline $\begin{array}{l}\text { PHMS_4VP_0.25 } \\
\text { without toluene }\end{array}$ & $\mathrm{D}^{\mathrm{H}}$ & -32.9 & 37 \\
& & -36.9 & 39 \\
PHMS_4VP_1.5 & $\mathrm{T}$ & -65.1 & 24 \\
without toluene & $\mathrm{D}^{\mathrm{H}}$ & -33.3 & 31 \\
& & & \\
& & -37.1 & 35 \\
PHMS_4VP_0.25 & $\mathrm{T}$ & -65.3 & 34 \\
in toluene & $\mathrm{D}^{\mathrm{H}}$ & -33.1 & 33 \\
& & -37.1 & 38 \\
& & -65.3 & 29 \\
PHMS_4VP_1.5 & $\mathrm{T}$ & -33.1 & 9 \\
in toluene & $\mathrm{D}^{\mathrm{H}}$ & & 42 \\
& & -36.5 & 49 \\
\hline
\end{tabular}

The PHMS_4VP samples contained more T units than PHMS functionalized with $N$-allyl compounds (relative contribution of T units: $9-11 \%$, Table 1). This can be explained by the lack of functionalization of the polymer with $4 \mathrm{VP}$ - hence, more $\mathrm{Si}-\mathrm{H}$ groups are prone to hydrolysis, as well as by higher reaction temperature $\left(110^{\circ} \mathrm{C}\right.$ for $4 \mathrm{VP}$ and $60{ }^{\circ} \mathrm{C}$ for $\mathrm{N}$-allyl compounds), which makes hydrolysis of $\mathrm{Si}-\mathrm{H}$ groups and subsequent condensation of $\mathrm{Si}-\mathrm{OH}$ groups faster. It should be also noted that the way of purification of the final PHMS_4VP samples may have also influenced the cross-linking reactions. Side processes could have occurred during extraction of the PHMS_4VP systems after synthesis, using toluene in a Soxhlet apparatus conducted for $24 \mathrm{~h}$ (Experimental Section) as well.

Thus, all the presented data show clearly that the reaction of PHMS with 4VP, as in the case of $\mathrm{M}_{2}{ }^{\mathrm{H}}$-despite modification of the conditions-does not occur. This confirms that Karstedt's catalyst is deactivated by pyridine moieties, which can be explained by their strong coordinative ability towards platinum. As previously reported, pyridine shows stronger affinity to platinum than amines since in its bonding with this metal not only the lone electron pair on nitrogen atom, but also $\pi$ electrons of the ring are involved [47]. Hence, a strong competition between coordination of $>\mathrm{C}=\mathrm{C}<$ bonds and pyridine moieties to Pt centers in the catalyst in these systems can be postulated.

As revealed in the studies, the only way by which $\mathrm{Si}-\mathrm{H}$ groups are transformed in the PHMS_4VP systems in the presence of Karstedt's catalyst is their hydrolysis followed 
by condensation of the $\mathrm{Si}-\mathrm{OH}$ groups formed. It is well known that platinum is a catalyst of hydrolysis of $\mathrm{Si}-\mathrm{H}$ groups; hence this process in the presence of $\mathrm{Pt}$ is facilitated.

The experiments conducted with $\mathrm{N}$-allyl compounds, discussed in the previous section, prove that hydrolysis of $\mathrm{Si}-\mathrm{H}$ groups can be a side reaction that accompanies hydrosilylation, i.e. hydrolysis of $\mathrm{Si}-\mathrm{H}$ groups does not preclude hydrosilylation. This supports the conclusion that deactivation of $\mathrm{Pt}$ centers in the catalyst, and not water present in the reaction medium, is the reason for the lack of $4 \mathrm{VP}$ hydrosilylation by PHMS.

It should be pointed out that our work demonstrates clearly that the most reliable technique to establish that hydrosilylation in the PHMS_4VP system does not take place is ${ }^{29} \mathrm{Si}$ NMR spectroscopy. Reported in Ref. [34, 35] materials prepared by treatment of PHMS-DMS copolymer with 4VP were not analyzed by this method. It seems therefore that their characterization was insufficient to conclude unambiguously that 4VP was hydrosilylated by PHMS-DMS copolymer.

Finally, it is worth mentioning that the presented results show that $\mathrm{M}_{2}{ }^{\mathrm{H}}$ is a good compound to perform model investigations on reactivity of 4VP in hydrosilylation by highmolecular-weight hydrosiloxanes in the presence of Karstedt's catalyst as was postulated in our previous work [36].

\section{Conclusions}

The studies conducted in the work on functionalization of polyhydromethylsiloxane (PHMS) by unsaturated nitrogen-containing organic compounds: $N$-allylaniline (Naa), $\mathrm{N}$-allylcyclohexylamine (Nach), $\mathrm{N}$-allylpiperidine (Nap) and 4-vinylpiridine (4VP) via hydrosilylation in the presence of Karstedt's catalyst show that:

1. Functionalization of PHMS by hydrosilylation in the presence of Karstedt's catalyst takes place only with the $\mathrm{N}$-allyl compounds, the reaction with $4 \mathrm{VP}$ does not proceed. This indicates that during the reactions of PHMS with $N$-allyl amines Pt catalyst is not deactivated while upon polymer treatment with 4VP catalyst's deactivation occurs. These findings are consistent with those obtained for hydrosilylation of all the studied $\mathrm{N}$-containing compounds by a low-molecular-weight hydrosiloxane $\left(\mathrm{M}_{2}{ }^{\mathrm{H}}\right)$.

2. Functionalization of PHMS with $N$-allyl amines in all the systems is not complete. For the samples with the higher amount of unreacted $\mathrm{Si}-\mathrm{H}$ groups left, crosslinking of the polymer, due to hydrolysis of $\mathrm{Si}-\mathrm{H}$ and subsequent condensation of silanol groups, is observed. These processes are the only ones that occur in PHMS_4VP systems.
3. Hydrosilylation of Naa, Nach and Nap with PHMS leads both, to the $\beta$ and $\alpha$ addition products, the former being the dominant one in all the cases. Hence, for the polymer the process is not as selective as for $\mathrm{M}_{2}{ }^{\mathrm{H}}$ which in the reactions with Naa and Nap gives exclusively the $\beta$ product. Thus, elongation of the hydrosiloxane chain reduces regioselectivity of the hydrosilylation reaction.

In conclusion, the studies show unequivocally that it is possible to prepare polysiloxanes containing amine side groups using a readily available and inexpensive polymer, PHMS and a simple reaction, hydrosilylation conducted under mild conditions with a highly efficient in this process Karstedt's catalyst. Thus functionalized polymers, due to high reactivity of amine moieties, may serve as starting compounds for further modifications leading to new materials of attractive properties, suitable for various applications.

Data availability The raw and the processed data required to reproduce these findings are available from the corresponding author upon reasonable requests.

Open Access This article is licensed under a Creative Commons Attribution 4.0 International License, which permits use, sharing, adaptation, distribution and reproduction in any medium or format, as long as you give appropriate credit to the original author(s) and the source, provide a link to the Creative Commons licence, and indicate if changes were made. The images or other third party material in this article are included in the article's Creative Commons licence, unless indicated otherwise in a credit line to the material. If material is not included in the article's Creative Commons licence and your intended use is not permitted by statutory regulation or exceeds the permitted use, you will need to obtain permission directly from the copyright holder. To view a copy of this licence, visit http://creativecommons.org/licenses/by/4.0/.

\section{References}

1. Lavis JM, Maleczka RE, Chandrasekaran V, Collier SJ (2016) In: Paquette LO, Crich D, Fuchs PL, Molander GA (eds) Encyclopedia of Reagents for Organic Synthesis. John Wiley \& Sons, Inc.

2. Lawrence NJ Drew MD Bushell SM 1999 Polymethylhydrosiloxane: a versatile reducing agent for organic synthesis J Chem Soc Perkin Trans 1 https://doi.org/10.1039/A903662H

3. Larson GL, Fry JL (2010) Ionic and Organometallic-Catalyzed Organosilane Reductions. John Wiley \& Sons Inc

4. Lipowitz J, Bowman SA (1973) The Use of Polymethylhydrosiloxane (PMHS) as a Reducing Agent for Organic Compounds. Aldrichimica Acta 6:1-6

5. Fieser LF, Fieser M (1974) Reagents for Organic Synthesis, vol 4. John Wiley \& Sons Inc, New York

6. Mazurek MH (2007) In: Mingos DMP, Crabtree RH (eds) Comprehensive Organometallic Chemistry III. Elsevier. https://doi.org/ 10.1016/B0-08-045047-4/00052-2

7. Curtis J, Colas A (2013) In: Ratner BD, Hoffmann AS, Schoen FJ, Lemons JE (eds) Biomaterials Science: An Introduction to materials in Medicine, 3rd edn. Elsevier Academic Press, London

8. Colombo P, Mera G, Riedel R, Sorarù GD (2010) PolymerDerived Ceramics: 40 Years of Research and Innovation in 
Advanced Ceramics. J Am Ceram Soc. https://doi.org/10.1111/j. 1551-2916.2010.03876.x

9. Marciniec B (1992) Comprehensive Handbook on Hydrosilylation. Pergamon Press. https://doi.org/10.1016/C2009-0-11185-6

10. Boutevin B, Guida-Pietrasanta F, Ratsimihety A (2000) In: Jones RG, Ando W, Chojnowski J (eds) Silicon-containing polymers. Springer, Dordrecht

11. Chechelska-Noworyta A, Mrówka J, Owińska M, Hasik M (2019) In: Koleżyński A, Król M (eds) Molecular SpectroscopyExperiment and Theory. Springer, Cham

12. Brook MA (2000) Silicon in organic, organometallic, and polymer chemistry. John Wiley\&Sons Inc.

13. Troegel D, Stohrer J (2011) Recent advances and actual challenges in late transition metal catalyzed hydrosilylation of olefins from an industrial point of view. Coord Chem Rev. https://doi.org/10. 1016/j.ccr.2010.12.025

14. El-Ashgar NM, El-Nahhal IM, Chehimi MM, Babonneau F, Livage J (2010) Extraction of $\mathrm{Co}, \mathrm{Ni}, \mathrm{Cu}, \mathrm{Zn}$ and $\mathrm{Cd}$ ions using 2-aminophenylaminopropylpolysiloxane. Environ Chem Lett. https://doi.org/10.1007/s10311-009-0223-0

15. Mefteh WB, Touzi H, Chevalier Y, Ouada HB, Othmane A, Kalfat R, Jaffrezic-Renault N (2014) Comparison of polysiloxane films substituted by undecenyl-cyclam and by naphthyl-cyclam for the design of ISFET devices sensitive to $\mathrm{Fe}^{3+}$ ions. Sens Actuators, B. https://doi.org/10.1016/j.snb.2014.07.129

16. Zawartka W, Pośpiech P, Cypryk M, Trzeciak AM (2015) Palladium supported on aminopropyl -functionalized polymethylsiloxane microspheres: Simple and effective catalyst forthe SuzukiMiyaura C-C coupling. J Mol Catal A. https://doi.org/10.1016/j. molcata.2015.07.002

17. Zawartka W, Pośpiech P, Cypryk M, Trzeciak AM (2016) Carbonylative Suzuki-Miyaura coupling catalyzed by palladium supported on aminopropyl polymethylsiloxane microspheres under atmospheric pressure of CO. J Mol Catal A. https://doi.org/10. 1016/j.molcata.2016.03.017

18. Wang Z, Beletskiy EV, Lee S, Hou X, Wu Y, Li T, Kung MC, Kung HH (2015) Amine-functionalized siloxane oligomer facilitated synthesis of subnanometer colloidal Au particles. J Mater Chem A. https://doi.org/10.1039/C4TA05954A

19. Lei Y, Zhou S, Dong C, Zhang A, Lin Y (2018) PDMS tri-block copolymers bearing quaternary ammonium salts for epidermal antimicrobial agents: Synthesis, surface adsorption and nonskinpenetration. React Funct Polym. https://doi.org/10.1016/j. reactfunctpolym.2018.01.007

20. Borkowski T, Zawartka W, Pospiech P, Mizerska U, Trzeciak AM, Cypryk M, Tylus W (2011) Reusable functionalized polysiloxanesupported palladium catalyst for Suzuki-Miyaura cross-coupling. J Catal. https://doi.org/10.1016/j.jcat.2011.06.023

21. Mieczyńska E, Borkowski T, Cypryk M, Pospiech P, Trzeciak AM (2014) Palladium supported on triazolyl-functionalized polysiloxane as recyclable catalyst for Suzuki-Miyaura cross-coupling. Appl Catal A. https://doi.org/10.1016/j.apcata.2013.10.032

22. Mizerska U, Fortuniak W, Chojnowski J, Hałasa R, Konopacka A, Werel W (2009) Polysiloxane cationic biocides with imidazolium salt (ImS) groups, synthesis and antibacterial properties. Eur Polym J. https://doi.org/10.1016/j.eurpolymj.2008.11.045

23. Grazulevicius JV, Strohriegl P, Pielichowski J, Pielichowski K (2003) Carbazole-containing polymers: synthesis, properties and applications. Prog Polym Sci. https://doi.org/10.1016/S00796700(03)00036-4

24. Claessens CG, Hahn U, Torres T (2008) Phthalocyanines: from outstanding electronic properties to emerging applications Chem Rec. https://doi.org/10.1002/tcr.20139

25. Nordin NH Othman N Ahmad Z (2013) Synthesis and thermal stability of cross-linked carbazole-substituted poly(dimethylsiloxane) for LED encapsulation Adv Mater Res https://doi.org/10.4028/ www.scientific.net/AMR.747.733

26. Nordin NH, Ramli MR, Othman N, Ahmad Z (2015) Synthesis of carbazole-substituted poly(dimethylsiloxane) and its improved refractive index. J Appl Polym Sci. https://doi.org/10.1002/app. 41654

27. Hua J, Li Z, Long K, Qin J, Li S, Ye C, Lu Z (2005) Synthesis and second order nonlinear optical properties of multifunctional polysiloxanes with sulfonyl based chromophores. J Polym Sci A. https://doi.org/10.1002/pola.20595

28. Moon IK, Oh JW, Kim N (2008) Synthesis and optical properties of benzocarbazolesubstituted polysiloxanes for polymeric photorefractive materials. J Photochem Photobiol A. https://doi.org/ 10.1016/j.jphotochem.2007.08.033

29. Li Z, Li J, Qin J, Qin A, Ye C (2005) Synthesis and characterization of polysiloxanes containing carbazolyl and sulfonyl-indole based chromophore as side chains. Polymer. https://doi.org/10. 1016/j.polymer.2004.09.079

30. Ganicz T, Makowski T, Stanczyk WA, Tracz A (2012) Side chain polysiloxanes with phthalocyanine moieties. Express Polym Lett. https://doi.org/10.3144/expresspolymlett

31. Kishi K, Ishimaru T, Ozono M, Tomita I, Endo T (2000) Development and Application of a Latent Hydrosilylation Catalyst. IX. Control of the Catalytic Activity of a Platinum Catalyst by Polymers Bearing Amine Moieties. J Polym Sci A.

32. Kanjilal B, Noshadi I, McCutcheon JR, Asandei AD, Parnas RS (2015) Allylcyclohexylamine functionalized siloxane polymer and its phase separated blend as pervaporation membranes for 1,3-propanediol enrichment from binary aqueous mixtures. J Membrane Sci. https://doi.org/10.1016/j.memsci.2015.03.025

33. Guerra-Contreras A, Villegas A, Ramirez-Oliva E, Cervantes J (2015) Characterization and Study of Properties in a Polar Solvent of a Functionalized and Quaternized Poly(dimethylsiloxaneco-methyl-hydridosiloxane). SILICON. https://doi.org/10.1007/ s12633-015-9286-7

34. Chen Y, Han Q, Wang Y, Zhang Q, Qiao X (2015) Synthesis of pyridinium polysiloxane for antibacterial coating in supercritical carbon dioxide. J Appl Polym Sci. https://doi.org/10.1002/app. 41723

35. Chen Y, Zhang Q, Ma Y, Han Q (2018) Surface-oriented fluorinated pyridinium silicone with enhanced antibacterial activity on cotton via supercritical impregnation. Cellulose. https://doi.org/ 10.1007/s10570-018-1657-y

36. Chechelska-Noworyta A, Owińska M, Hasik M (2019) Hydrosilylation of nitrogen-containing organic compounds: Model Studies. J Organomet Chem. https://doi.org/10.1016/j.jorganchem. 2019.07.017

37. Socrates G (2004) Infrared and Raman characteristic group frequencies, 3rd edn. John Wiley \& Sons Inc., New York

38. Antić VV, Antić MP, Govedarica MN, Dvornić PR (2007) Kinetics and Mechanism of the Formation of Poly[(1,1,3,3-tetramethyldisiloxanyl)ethylene] and Poly(methyldecylsiloxane) by Hydrosilylation. J Polym Sci A. https://doi.org/10.1002/pola.21992

39. Nyczyk A, Paluszkiewicz C, Hasik M, Cypryk M, Pospiech P (2012) Cross-linking of linear vinylpolysiloxanes by hydrosilylation - FTIR spectroscopic studies. Vib Spectrosc. https://doi.org/ 10.1016/j.vibspec.2012.01.002

40. Clayden J, Greeves N, Warren S, Wothers P (2012) Organic Chemistry, 2nd edn. Oxford University Press, Oxford

41. Blackburne ID, Katritzky AR, Takeuchi Y (1975) Conformation of piperidine and of derivatives with additional ring hetero atoms. Acc Chem Res. https://doi.org/10.1021/ar50093a003

42. Smith AL (1960) Infrared spectra-structure correlations for organosilicon compounds. Spectrochim Acta. https://doi.org/10.1016/ 0371-1951(60)80074-4 
43. Saalwächter K (2019) In: Zhang R, Miyoshi T, Sun P (eds) NMR Methods for Characterization of Synthetic and Natural Polymers. Royal Soc of Chem. https://doi.org/10.1039/978178801648300001.

44. Taylor RB, Parbhoo B, Fillmore DM (1991) In: Smith AL (ed) The Analytical Chemistry of Silicones. John Wiley \& Sons, Inc.

45. Yactine B, Boutevin B, Ganachaud F (2009) Do-it-yourself functionalized silicones part 1:basic methods for characterization of commercial products. Polym Adv Technol. https://doi.org/10. $1002 /$ pat. 1281
46. Bayari S, Yurdakul S (2000) Fourier Transform Infrared and Raman Spectra of 4-vinylpyridine and its Transition Metal(II) Tetracyanonickelate Complexes. Spectrosc Lett. https://doi.org/ 10.1080/00387010009350132

47. Davies JA, Hartley FR (1981) Complexes of the platinum metals containing weak donor ligands. Chem Rev. https://doi.org/10. 1021/cr00041a004

Publisher's Note Springer Nature remains neutral with regard to jurisdictional claims in published maps and institutional affiliations. 